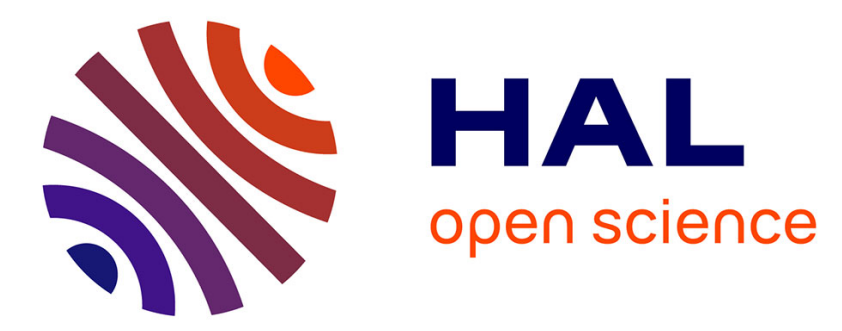

\title{
Structural and magnetic properties of $\mathrm{Ru} / \mathrm{Ni}$ multilayers
}

K Mergia, A Tomou, I Panagiotopoulos, F Ott

\section{To cite this version:}

K Mergia, A Tomou, I Panagiotopoulos, F Ott. Structural and magnetic properties of Ru/Ni multilayers. Journal of Physics D: Applied Physics, 2011, 44 (7), pp.75001. 10.1088/0022-3727/44/7/075001. hal-00594971

\section{HAL Id: hal-00594971 \\ https://hal.science/hal-00594971}

Submitted on 23 May 2011

HAL is a multi-disciplinary open access archive for the deposit and dissemination of scientific research documents, whether they are published or not. The documents may come from teaching and research institutions in France or abroad, or from public or private research centers.
L'archive ouverte pluridisciplinaire HAL, est destinée au dépôt et à la diffusion de documents scientifiques de niveau recherche, publiés ou non, émanant des établissements d'enseignement et de recherche français ou étrangers, des laboratoires publics ou privés. 


\title{
Structural and magnetic properties of $\mathrm{Ru} / \mathrm{Ni}$ multilayers
}

\author{
K Mergia ${ }^{1}$, A Tomou ${ }^{2}$, I Panagiotopoulos ${ }^{2}$, F Ott $^{3}$ \\ ${ }^{1}$ National Center for Scientific Research Demokritos, Institute of Nuclear Technology and Radiation Protection, Aghia \\ Paraskevi, Athens, 15310, Greece \\ ${ }^{2}$ Dept. of Materials Science and Engineering, University of Ioannina, Ioannina 45110, Greece \\ ${ }^{3}$ Lab. Léon Brillouin CEA/CNRS, Centre d'Etudes de Saclay, France \\ E-mail: ipanagio@cc.uoi.gr and kmergia@ipta.demokritos.gr
}

\begin{abstract}
.
$\mathrm{Ru} / \mathrm{Ni}$ multilayers of different $\mathrm{Ni}$ thickness have been fabricated using magnetron sputtering. The structure of the multilayers has been determined by grazing incidence X-ray diffraction and X-ray reflectivity and their magnetic properties by magnetization and polarized neutron reflectivity measurements. The presence of $\mathrm{Ru}$ leads to the formation of a hexagonal $\mathrm{Ni}$ structure within interfacial layer $\sim 1 \mathrm{~nm}$ above each $\mathrm{Ru}$ layer, while the rest of the Ni layer relaxes to the equilibrium fcc structure. The hcp $\mathrm{Ni}$ interfacial layer has a substantially increased cell volume is ferromagnetic with an atomic magnetic moment that increases with $\mathrm{Ni}$ layer thickness but remains lower than the value predicted from ab initio calculations.
\end{abstract}

Keywords: hcp Ni, Ru/Ni multilayers, thin magnetic films, polarized neutron reflectivity

PACS: 75.70.Cn Magnetic properties of interfaces (multilayers, superlattices, heterostructures), 68.65.Ac Multilayers, 61.05.cp X-ray diffraction, 61.05.fj Neutron reflectometry, 61.05.cm X-ray reflectometry (surfaces, interfaces, films)

\section{Introduction}

Layered magnetic structures are now the basis for several technological applications from spin valves and magnetic random access memories to ultra high density recording hard disk media. In several applications as laminated recording media [1], flux concentrators [2], and various synthetic ferrimagnetic [3] and anti-ferromagnetic [4] structures, ruthenium is a usual choice as an interlayer material providing anti-ferromagnetic coupling between magnetic layers. Recently, it has been demonstrated that the incorporation of lattice mismatched or structurally incoherent layers between soft magnetic layers can lead to a significant reduction in saturation and coercive fields [5] due to suppression of stripe domains. Soft magnets as permalloys and iron-cobalt alloys crystallize in cubic structures and are thus structurally incompatible with hexagonal $\mathrm{Ru}$. The existence of interfacial magnetically "dead" [6] or "weak" layers has been reported in NiFe/Ru multilayers [7] but their origin remains unclear. The interfacial moments of $3 \mathrm{~d}$ elements as Ni depend sensitively on contributions, such as strain, chemical intermixing and surface structure and morphology [8]. It must be noted that growth on Ru layers can induce the hexagonal structure on layers that normally have a cubic structure as $\mathrm{Fe}[9]$. 
In the following we report on the magnetic and structural properties of Ru/Ni multilayers. It is found that the use of $\mathrm{Ru}$ interlayers leads to the formation of hexagonal $\mathrm{Ni}$ at the interfaces which disrupts the coupling between the magnetic layers and thus can be used to reduce the saturation and coercive fields.

\section{Experimental}

The Ru/Ni multilayered films have been deposited on Si wafers at room temperature using a MANTIS magnetron sputtering system and employing $\mathrm{Ni}\left(3^{\prime \prime}\right.$ diameter) and $\mathrm{Ru}\left(2^{\prime \prime}\right)$ sources in confocal geometry. The sources point at an angle of 45 degrees to the (horizontal) substrate plane, which is rotated during the deposition. Prior to the deposition the chamber was evacuated to a base pressure of $7 \times 10^{-5} \mathrm{~Pa}$. The target to substrate distance is $15 \mathrm{~cm}$ and the process gas (Ar) pressure during deposition was $0.18 \mathrm{~Pa}$. The Ni layers were deposited at a rate of $0.047 \mathrm{~nm} / \mathrm{sec}$ by applying $50 \mathrm{~W}$ direct current power and the $\mathrm{Ru}$ layers at a rate of $0.01 \mathrm{~nm} / \mathrm{sec}$ by applying $120 \mathrm{~W}$ of radiofrequency power (13.56 MHz). Multilayered samples of the nominal form $\mathrm{Si} / \mathrm{Ru}(9 \mathrm{~nm}) /[\mathrm{Ru}(1.5 \mathrm{~nm}) / \mathrm{Ni}(\mathrm{t} \mathrm{nm})]_{8}$ with $\mathrm{t}_{\mathrm{Ni}}$ from 0.8 to $4.5 \mathrm{~nm}$ were fabricated. In addition, $\mathrm{Ni}$, Ru single layer samples and a Ru/Ni bilayer were deposited under the same conditions.

The layer structure was assessed by X-ray reflectivity measurements (XRR) performed on a D8 Advance Bruker diffractometer using $\mathrm{Cu}-\mathrm{K}_{\alpha}$ radiation and parallel beam stemming from a Göbel Mirror. The XRR measurements were analyzed using the Leptos software [10] which is based on Parratt's formalism. Structural depth sensitive information was obtained by the employment of grazing incidence X-ray diffraction (GIXRD) measurements carried out on the D8 instrument. Different angles of incidence were used either to get depth sensitive information or to distinguish between Bragg reflections and multilayer structure satellites.

Magnetic measurements were carried out using a Lake Shore vibrating sample magnetometer (VSM). The multilayer Ru/Ni magnetic structure was determined by Polarized Neutron Reflectivity (PNR) measurements at PRISM instrument at Laboratoire Léon-Brillouin, CEA-Saclay. The PNR measurements were performed at room temperature and with an in-plane external magnetic field of $0.275 \mathrm{~T}$ in order to magnetically saturate the samples and align the magnetic domains. The incident neutron wavelength was $0.43 \mathrm{~nm}$ and the Q-range varied from 0.05 to $2.3 \mathrm{~nm}^{-1}$. The neutron spin-up and spin-down reflectivities (R+, R-) were least squares fitted using the SimulReflec software [11]. 


\section{Experimental results}

\subsection{X-ray diffraction measurements}

In order to assess the crystal structure of the layers GIXRD measurements were carried out on all $\mathrm{Ru} / \mathrm{Ni}$ multilayers. The GIXRD patterns for all the Ru/Ni multilayers are presented in figure 1 together with the spectrum from the $12 \mathrm{~nm} \mathrm{Ru}$ single layer which was deposited under the same conditions. The $\mathrm{Ru}$ hexagonal structure is clearly observed in the $12 \mathrm{~nm}$ single Ru layer. The sharp Bragg peaks observed in the 50-52 degrees region stem from the single crystal Si substrate.

In the GIXRD patterns from Ru/Ni multilayers (figure 1), hexagonal Ru Bragg peaks arise from two sources, the one attributed in the $9 \mathrm{~nm} \mathrm{Ru}$ buffer layer (crosses in figure 1) and the other arising from the $\mathrm{Ru}$ layers in the multilayer structure (stars in figure 1). This Bragg peak assignment is confirmed by the GIXRD spectra of figure 2. These spectra have been received for decreasing values of the incidence angle $\alpha$. As the incidence angle decreases and approaches the angle for total reflection (around 0.4 deg., see figure 5) the X-ray beam penetrates mostly the top layers and thus the XRD spectrum arises from the top layers. Under these conditions, it is expected the Bragg reflections arising from the Ru buffer layer to be relatively decreasing in comparison to the reflections of the Ru layers. This is what is indeed observed in figure 2 .

The remaining Bragg peaks are obviously arising from $\mathrm{Ni}$ and it is convenient for the discussion of the methodology of their assignment to concentrate on the $4.5 \mathrm{~nm}$ Ni multilayer diffraction pattern in figure 1. The two peaks at around 44.5 and 52 degrees can be attributed to cubic Ni with a lattice constant of $0.354 \mathrm{~nm}$, which is close to the cubic Ni bulk value. The Bragg peaks appearing in the $2 \theta$ range 36 to 39 degrees can only be attributed to hexagonal Ni. In $\$ 3.2 .2$ from the analysis of the PNR data it will be shown that the hexagonal $\mathrm{Ni}$ is formed at the $\mathrm{Ru}$ interface. The last unassigned peak is that at around 45.5 degrees and its origin will be discussed in the next paragraph.

In order to tackle the ambiguities arising from peak overlap, several scans recorded at different incidence angles, $\alpha$, as well as conventional $\theta-2 \theta$ scans have been compared for each sample in order to: (i) separate the contribution of the $\mathrm{Ru}$ buffer layer from those of the $\mathrm{Ru} / \mathrm{Ni}$ multilayer structure (discussed above), (ii) verify that the observed peaks are Bragg reflections as opposed to satellites due to the multilayer periodicity and, (iii) acquire information for the crystallographic texture. Examples of such scans are given in figures 2 and 3. Due to refraction effects the position of the Bragg peaks depends on the incidence angle. As the incidence angle decreases the Bragg peaks are shifted to higher angles [12]. However, the relative separation, $\Delta(2 \theta)$, of the Bragg peaks does not depend on the incidence angle and this distinguishes the Bragg peaks from the satellite peaks of the multilayer structure. An example of the independence of the $\Delta(2 \theta)$ separation on the incidence angle 
is demonstrated in the inset of figure 3, where the separation $\Delta(2 \theta)$ between the peak at around 41 deg. and the peak at around 44 deg. is displayed ( $\square,(a))$. The peaks assigned as Bragg peaks in figure 1 and discussed in the previous paragraph fulfill the requirement of constant $\Delta \theta$ separation for different angles of incidence. On the contrary, because the projection of the periodicity of the compositional modulation of the multilayer along the scattering vector decreases, the angle separation of a satellite peak with respect to a Bragg peak increases with increasing angle of incidence [13]. From the data points (b) (•) in the inset of figure 3 we observe that the angle difference between the peak at around 45.5 deg. and the Bragg peak at around $44 \mathrm{deg}$. increases with increasing angle of incidence. Thus, the peak at around $45.5 \mathrm{deg}$. is not a Bragg peak but arises from the superlattice structure.

From the GIXRD patterns the hexagonal $\mathrm{Ru}$ and Ni layer lattice constants (a and c) were determined (Table 1). For the calculation of the lattice constants profile matching was used to determine the exact positions of overlapping nearby peaks and also the shift of the Bragg peaks due to refraction effects has been taken into account. The lattice constants of the two hexagonal phases ( $\mathrm{Ru}$ and Ni) as a function of the nominal Ni layer thickness are presented in figure 4 with the corresponding bulk values [14] shown as straight lines. The lattice constants of the single Ru layer (zero Ni thickness in figure 4) are very close to the expected bulk values. The same holds for the cubic Ni structure (PDF: 65-2865). Standard $\theta-2 \theta$ XRD scans show that Ni tends to grow with (111) texture, as typically occurs in sputtered films of cubic metallic structures. The Ru layers have (002) texture for Ni thickness up to $1.5 \mathrm{~nm}$. This texture is lost for $\mathrm{t}_{\mathrm{Ni}}$ above $3.0 \mathrm{~nm}$ and must be related to the mechanisms of relaxation of interfacial misfit strains [15].

\section{$3.2 X$-ray reflectivity measurements (XRR)}

In order to analyze the XRR measurements a model of the multilayer structure has to be incorporated in the least squares procedure. Taking into account that the GIXRD measurements showed that both hexagonal and cubic Ni phases co-exist in the samples two models were examined. The one model supposes that the two phases are separated and thus the Ni layer is composed by two sublayers having different densities. In the second model is assumed that the two phases are mixed forming a Ni layer without any sharp interface. Using simulations or data fitting, it was concluded that the XRR measurements can not distinguish between these two models (i.e. all the experimental data features can be fitted by either model). As the parameters deduced from XRR measurements refer to average values, the model of constant density Ni layer encompasses also that of two sublayers and therefore it was used for the deduction of the different parameters. 
In figures 5 and 6 the $\mathrm{XRR}$ patterns for the $[\mathrm{Ru}(1.5 \mathrm{~nm}) / \mathrm{Ni}(4.5 \mathrm{~nm})] \times 8$ and the $[\mathrm{Ru}(1.5 \mathrm{~nm}) / \mathrm{Ni}(1.0 \mathrm{~nm})] \times 8$ multilayer, respectively, are shown. The XRR measurements were performed up to $2 \theta=8^{\circ}$ and thus up to the $4^{\text {th }}$ order Bragg peaks have been observed. The structural parameters i.e. thickness, density and roughness of each layer, were determined by least squares fitting of the calculated reflectivity values to the experimental data. The solid lines in figures 5 and 6 are the least-squares fit to the XRR data. It can be observed that there is a very good agreement between the experimental data and the fitted curve. The structural data as determined by least square fit to the XRR data are summarized in Table 1. The determined thickness values are close to the nominal ones. Also, the mass densities obtained for the Ru and Ni layers are very close to the bulk ones.

\subsection{Magnetometry}

In figure 7 the hysteresis loops for a series of $\mathrm{Si} / \mathrm{Ru}(9 \mathrm{~nm}) /[\mathrm{Ru}(1.5 \mathrm{~nm}) / \mathrm{Ni}(\mathrm{t} \mathrm{nm})]_{8}$ multilayers are shown. A loss in magnetic moment as the $\mathrm{Ni}$ layers become thinner can be observed. The measurements shown were performed with the applied field parallel to the substrate. In contrast to the low saturation fields of the in-plane magnetization curves, when measured with the applied field perpendicular to the film plane they have a linear part that saturates above $0.3 \mathrm{~T}$. This shows the presence of a typical easy-plane shape anisotropy. The films are polycrystalline and the substrate is rotated during the deposition, so no anisotropy axis within the plane is expected.

Antiferromagnetic coupling between layers would manifest by an increase of the saturation field, typical in synthetic antiferromagnets [16], not observed here. For a Ru thickness of $1.5 \mathrm{~nm}$ minimal interlayer RKKY coupling is expected [17]. The structural incompatibility between the $\mathrm{Ru}$ and $\mathrm{Ni}$ layers further reduces the possibility of exchange coupling between them. The only possible source of interlayer coupling remains the dipolar interaction between the nickel layers as a result of the correlated roughness at the interfaces [18]. However the magnetic data shown below imply that the interlayer coupling is negligible as layering reduces both saturation and coercivity fields: In figure 8 the hysteresis loop of a $[\mathrm{Ru}(1.5 \mathrm{~nm}) / \mathrm{Ni}(4.5 \mathrm{~nm})]_{10}$ multilayer is compared to that of a Ni single layer with the same total Ni thickness $(45 \mathrm{~nm})$. The comparison is done between two films with the same total $\mathrm{Ni}$ thickness. There is a striking reduction in saturation $\left(\mathrm{H}_{\mathrm{S}}\right)$ and coercive fields $\left(\mathrm{H}_{\mathrm{C}}\right)$ by interlayering with $\mathrm{Ru}$ : While the single layer $\mathrm{Ni}$ film has an $\mathrm{H}_{\mathrm{S}}$ of $600 \mathrm{Oe}$ and $\mathrm{H}_{\mathrm{C}}$ of $160 \mathrm{Oe}$, these drop to $\mathrm{H}_{\mathrm{S}}=67 \mathrm{Oe}$ and $\mathrm{H}_{\mathrm{C}}=20 \mathrm{Oe}$ in the multilayer. The shape of the loop of the single Ni layer is characteristic of the existence of stripe domains [19]. It is known that in soft magnetic thin films above a critical thickness an abrupt increase of coercivity and saturation field occurs (for instance in permalloy $320 \mathrm{~nm}$ ) which is related to the formation of stripe domains [20]. In single layer Ni films sputtered under the same conditions with the Ru/Ni multilayers of our study this happens suddenly at 
$40 \mathrm{~nm}$. This low critical value must be attributed to the fact that the nickel tends to grow with the (111), the easy magneto-crystalline anisotropy axis, perpendicular to the film plane. Of course with the exception of very thin films (few monolayers) in which interface and elastic anisotropies prevail, shape anisotropy dominates the magnetocrystalline one in $\mathrm{Ni}$ thin films, thus the magnetization is expected to lie within the film plane. However, the conditions are favorable for the creation of stripe domains [21] having a component of the magnetization out of the film plane. Therefore the mechanism through which Ru interlayering makes the magnetic properties softer seems to be related to the suppression of the formation of this domain structure due to decoupling. This has been proposed as a practical way to retain the soft properties in applications that require thick ferromagnetic layers [5]. The advantage is lost for thinner Ni layers below the critical thickness. For instance a Ni layer of $12 \mathrm{~nm}$ thickness has a $\mathrm{H}_{\mathrm{S}}=50$ Oe and $\mathrm{H}_{\mathrm{C}}=25 \mathrm{Oe}$ (figure 7).

\subsection{Polarized Neutron Reflectometry}

The PNR spectra were measured for the samples with Ni layer thickness of $t=4.5,3.0$ and $1.5 \mathrm{~nm}$. For the fitting of the PNR data both a structural and a magnetic model have to be incorporated in the least squares fitting. In order to reduce the number of parameters to be fitted by the least squares procedure the structural parameters determined by XRR formed the basis for the structural models used for the interpretation of the PNR spectra. GIXRD measurements have shown that cubic and hexagonal Ni phases co-exist in all the samples. There are two possibilities, either the Ni two phases are mixed in the Ni layer or the Ni layer is divided into two sublayers, one having cubic $\mathrm{Ni}$ and the other $\mathrm{Ni}$ hexagonal structure. The second possibility was also considered for the modeling of the XRR data but it was found that XRR can not distinguish between the two possibilities. However, existence of separate cubic and hexagonal layers is physically reasonable and might result to different magnetic structures. As PNR is a probe for the multilayer magnetic structure it could distinguish such a formation. Thus, for the PNR measurements simulations of both of separate Ni layers (cubic and hexagonal) or one type Ni layer have to be taken into account. As a result, the PNR data were least square fitted considering two general models. In the first model (model A) it was assumed that the Ni layer contains grains of both hexagonal and cubic structures and thus in the reflectivity simulations can be presented as one layer with an average density and magnetization. In the second model (model B) it was assumed that the hexagonal and cubic Ni form different layers. Since from the GIXRD measurements it has been found that both cubic and hexagonal $\mathrm{Ni}$ structures are present in the samples it can be assumed that the Ni hexagonal structure grows on the top of the hexagonal $\mathrm{Ru}$. In all models the magnetic moment, thickness and roughness of each Ni layer were parameters to be fitted. Also the 
Ru layer magnetic moment was a fitted parameter thus magnetic and non magnetic Ru layer models could be examined.

Figure 9 shows the PNR data from $[\mathrm{Ru}(1.5 \mathrm{~nm}) / \mathrm{Ni}(4.5 \mathrm{~nm})] \times 8$ multilayer. The dashed line in figure 9 is the least square fitted curve for model $\mathrm{A}$ assuming that the Ru layers are non magnetic. It is observed that model A fails to describe the region around the second Bragg peak. This is also observed even if the $\mathrm{Ru}$ layer magnetic moment is a fitted parameter i.e. the least squares minimization procedure results to a curve which does not describe the experimental data. This demonstrates that a single Ni layer model is not consistent with the experimental PNR data.

In model $\mathrm{B}$, initially, we let the magnetic moments of the three layers free to vary (i.e. as fitted parameters $\mathrm{m}(\mathrm{Ru}) \neq 0, \mathrm{~m}\left(\mathrm{Ni}_{\text {hex }}\right) \neq 0$ and $\left.\mathrm{m}\left(\mathrm{Ni}_{\text {cub }}\right) \neq 0\right)$ and for each PNR spectrum the three magnetic moments are determined by a least squares fit. For each determined value its error is estimated. This estimation is performed by simulating reflectivity curves for larger and smaller values than the least squares one. The error limits are determined from an obvious discrepancy between the calculated and the least squares curve. This procedure is in principle a sensitivity test which includes the statistical errors and takes into account the situation in which the least squares minimum for a parameter is flat. Using this procedure it has been found that the $\mathrm{Ru}$ magnetic moment and for the three measured samples would be zero taking into account the errors. The last statement can be interpreted as there is no observable difference between a reflectivity curve corresponding to non-magnetic $\mathrm{Ru}$ or to a $\mathrm{Ru}$ with the small magnetic moment determined by the least squares fit (this applies to any set of $\mathrm{Ni}$ moments). Thus, we may conclude that there is no measurable induced magnetic moment in Ru. As the calculated reflectivity curve is not sensitive to small values of the Ru moment this was set equal to zero and the magnetic moment of the two Ni layers was determined by the least squares fit (Table 2). The fitted reflectivity curves for $[\mathrm{Ru}(1.5 \mathrm{~nm}) / \mathrm{Ni}(4.7 \mathrm{~nm})] \times 8$ multilayer employing model $\mathrm{B}$ are the solid lines in figure 9.

From Table 2 we observe that the Ni1 layer (on the top of Ru) has the smallest magnetic moment per atom and thus we can infer that this layer corresponds to the hexagonal Ni. This is further corroborated from the fact that the magnetic moment of the $\mathrm{Ni} 2$ layer $\left(0.61 \mu_{B}\right)$ for the $[\mathrm{Ru}(1.5 \mathrm{~nm}) / \mathrm{Ni}(4.5 \mathrm{~nm})] \mathrm{x} 8$ sample is similar to the bulk value of the cubic Ni $\left(0.606 \mu_{B}\right)$. We also observe that the magnetic moments for both cubic and hexagonal Ni layers increase as the thickness of the layer is increased. Also the thickness of the hexagonal Ni layer on the top of the hexagonal Ru is around $1 \mathrm{~nm}$ and almost independent of the nominal deposited Ni thickness. This thickness corresponds to about two deposited $\mathrm{Ni}$ atomic layers and indicates the extent of $\mathrm{Ru}$ influence on the overlaid $\mathrm{Ni}$. 


\section{Discussion and Conclusions}

The actual thickness of $\mathrm{Ni}$ and $\mathrm{Ru}$ layers, their density and interfacial roughness as determined from the XRR measurements are summarized in Table 1. It should be noted that these values represent the averages of all eight bilayers of the multilayer structure. The density of Ni is almost constant for all the multilayer samples, close to that of the bulk, except for the multilayer of Ni nominal thickness of $1.5 \mathrm{~nm}$ for which is around $13 \%$ lower than that of the bulk. For thin Ni layers $\left(\mathrm{t}_{\mathrm{Ni}}<1.5 \mathrm{~nm}\right)$ the density of the Ru layers is lower (5\% than the bulk) a fact that may be related with the presence of the $\mathrm{Ni}$ hexagonal layer on top of the Ru layer which results in a lower effective density of Ru and this reduction is more pronounced for the thinner layers. For thicker Ni layers $\left(t_{\mathrm{Ni}}>1.5 \mathrm{~nm}\right)$ the $\mathrm{Ru}$ density is that of the bulk corresponding to thinner Ru layers $(\approx 1.7 \mathrm{~nm})$. Therefore, we may conclude that the thickness of the deposited Ni layer influences the structure of deposited Ru layers and that there is a critical Ni layer thickness of $1.5 \mathrm{~nm}$.

GIXRD measurements show that both cubic and hexagonal Ni phases are present in all the multilayer samples. The lattice constant of the cubic Ni is very close to that of the bulk. PNR measurements show that the hexagonal $\mathrm{Ni}$ lies on the top of the hexagonal $\mathrm{Ru}$ and its thickness is about $1 \mathrm{~nm}$ irrespectively of the total thickness of the deposited Ni layer. It represents a critical thickness above which the structure relaxes to the equilibrium bulk $\mathrm{Ni}$ structure. Some analogous examples can be found in $\mathrm{Ni}$ nanoparticles. Bulk $\mathrm{Ni}$ as well as Ni nanoparticles naturally crystallize into face-centered-cubic (fcc) with ferromagnetic properties. Preparation of an hexagonal close packed (hcp) Ni powder was reported for the first time, via reduction of divalent Ni with a Potassium-Boron liquid alloy [22]. The XRD pattern of the sample appears as the standard database card (no. 45-1027) with $\mathrm{a}=0.2653 \mathrm{~nm}$ and $\mathrm{c}=0.4348 \mathrm{~nm}$ [14]. The hcp structure was found to be stable at temperatures up to $380^{\circ} \mathrm{C}$ above which it transforms to fcc. Since this report hcp Ni or mixtures of fcc and hcp nanoparticles have been fabricated by different routes $[22,23,24,25,26,27,28]$. The produced hcp Ni nanoparticles give a wide range of lattice constants i.e. $a_{\mathrm{Ni}(\mathrm{hcp})}$ varies from 0.250 to $0.265 \mathrm{~nm}$ and $c_{\mathrm{N}(\mathrm{hcp})}$ from 0.397 to $0.435 \mathrm{~nm}$ resulting in a c/a ratio variation from 1.59 to 1.64 [29] the ideal hcp being 1.633. The average (over all the fabricated samples) lattice constant, $\langle\mathrm{a}\rangle_{N i(h c p)}=(0.257 \pm 0.007) \mathrm{nm}$ is within the lattice constants found for the $\mathrm{Ni}$ (hcp) nanoparticles, whereas $\langle\mathrm{c}\rangle_{N i(h c p)}=(0.45 \pm 0.01) \mathrm{nm}$ is higher. Therefore the disturbed $\sim 1 \mathrm{~nm}$ thick hcp Ni layer has on average similar $\langle\mathrm{a}\rangle_{N i(h c p)}$ lattice constant as the hcp nanoparticles but its $\langle\mathrm{c}\rangle_{N i(h c p)}$ lattice constant is substantially dilated resulting in the ratio $\mathrm{c} / \mathrm{a}=1.75$. The large atomic volume expansion $+18 \%$ is comparable to those of $\mathrm{Fe}$ observed in $\mathrm{Fe} / \mathrm{Ru}$ supperlattices ranging from $+14 \%$ [9] to $25 \%$ [30] above the value of the $\varepsilon$ - $\mathrm{Fe}$ and $\mathrm{Cr}$ in $\mathrm{Cr} / \mathrm{Ru}$ supperlattices [31]. 
$\mathrm{Ab}$ initio calculations [32] show that the total energy of the magnetic hep $\mathrm{Ni}$ is about $0.02 \mathrm{eV} /$ atom (non-magnetic $0.05 \mathrm{eV} /$ atom) higher than that of FM fcc Ni. Therefore the stabilization of the hcp Ni phase can be attributed to impurity atoms introduced during the Ni nanoparticle fabrication or surface effects. There is direct experimental evidence that the Ni hcp phase formation arises in systems with high surface to volume ratio. Ni particles, prepared after chemical reduction of nickel salts by activated sodium hydride in organic solvents, have an hcp structure in sizes smaller than $4 \mathrm{~nm}$ whereas larger particles are fcc [33]. Hcp nickel islands grown on the (001) surface of $\mathrm{MgO}$ transform into the normal fcc structure when the size of the islands exceeds a critical value of about $2.5 \mathrm{~nm}$ [34]. Furthermore proximity to hexagonal structures can stabilize hcp-Ni. For instance hcp-Ni film produced by electrodeposition on a hcp Co single crystal reverted to fcc structure at room temperature after being stripped from the substrate [35]. There is also an Ar-gas pressure window in magnetron sputtering that favors the growth of stable single-phase hexagonal nanocrystalline Ni films [36]. It may, thus, be concluded that the Ni deposited on the top of the Ru film takes the hcp structure as Ru$\mathrm{Ni}$ interface interaction makes hcp structure energetically more favorable than fcc. The critical thickness of this pseudomorphic hcp-Ni growth is estimated to $1 \mathrm{~nm}$ as the hcp Ni layer thickness determined by PNR is about $1 \mathrm{~nm}$ irrespectively of the deposited Ni layer total thickness. This result is in concord with the observed hcp Fe structure in MBE deposited Fe/Ru [37] and the experimental results on Fe/Ru multilayers prepared by high-vacuum electron-gun evaporation which show that even a $0.6 \mathrm{~nm}$ thick $\mathrm{Ru}$ layer can force to up $1.2 \mathrm{~nm}$ thick Fe layer the hcp metastable structure [30]. In $\mathrm{Cr} / \mathrm{Ru}$ superlattices $\mathrm{Cr}$ layers thinner than $0.8 \mathrm{~nm}$ adopt a slightly distorted hcp structure, accompanied by a large atomic volume expansion [31]. Therefore the hcp Ru constrains the as deposited Ni atoms into the hcp structure. As the deposited Ni thickness increases above $1 \mathrm{~nm}$, the Ru-Ni interface effect is minimized and thus the bulk stable Ni fcc phase develops. The difference between hcp and fcc structures can be thought of as a result of different stacking sequences of closed pack atomic layers $(A B A B$ vs $A B C A B C$ ). Geometrically the transition hcp $\rightarrow$ fcc can be realized by a sliding on the (111) fcc plane along the direction [112] fcc by a vector of $1 / 3$ [112] fcc but the condition $a_{h c p}=a_{f c c} / \sqrt{2}$ implied by this sliding mechanism is not obeyed by the lattice constants of hcp and fcc Ni. In fact there is a lattice mismatch of $6 \%$ which probably gives rise to strain relaxation mechanisms within the critical thickness of $1 \mathrm{~nm}$. The average coherence length [38] in the vertical direction $(\theta-2 \theta$ XRD scans) varies from 9.6 to $12.8 \mathrm{~nm}$ for the thinnest and thickest multilayer, respectively. This shows that the atomic layers sequence in the growth direction is correlated for about 2 (thickest multilayer) to 3.5 (thinner multilayer) bilayers which indicates some degree of columnar growth [39]. The in-plane 
diameter of the columns is around $10.6 \mathrm{~nm}$ as derived by applying the Scherrer formula to the GIXRD peaks.

Summarizing the above discussion in all the multilayers the first $1 \mathrm{~nm}$ of the deposited Ni grows in the metastable hcp structure and this can be attributed to Ni-Ru interface. The rest of the deposited $\mathrm{Ni}$ layer has the equilibrium fcc structure. The $1 \mathrm{~nm}$ thick hcp Ni experiences two interface interactions, one from the hcp $\mathrm{Ru}$ and the other from the fcc Ni. Interface interactions resulting to phase transformations and/or stresses to the respective layer decay rapidly with distance from the interface and it is expected to exist a critical distance after which the bulk properties prevail. As the experimentally determined values are averages over the whole thickness of the layer we shall expect that thin layers values represent the interface structure whereas for thick layers the interface structure will slightly influence the average which will be leaning towards the bulk properties. The experimental values for intermediate thickness layers will reflect both the interface and bulk structures. This indeed is observed in figure 4. Both the $a$ and $c$ lattice constants of both hexagonal $\mathrm{Ni}$ and $\mathrm{Ru}$ for $\mathrm{t}_{\mathrm{Ni}}$ above 3 $\mathrm{nm}$ tend to the respective bulk values. For smaller Ni layer thickness the hexagonal Ni lattice is expanded in both the a and c directions by around $6 \%$. On the contrary the Ru lattice is compressed with the maximum deviation $(\Delta \mathrm{a} / \mathrm{a} \sim-5 \%, \Delta \mathrm{c} / \mathrm{c} \sim-2 \%)$ at $1.5 \mathrm{~nm}$ (figure 4). Notwithstanding there is a change of the lattice contents of both hexagonal Ru and Ni versus Ni layer thickness the c/a ration for both is almost Ni layer thickness independent. From the data of Table 1 it is found that $\langle c / a\rangle=1.64 \pm 0.02$ and $\langle c / a\rangle_{R u}=1.62 \pm 0.01$, where the mean value is over all the fabricated multilayers. From ab initio calculations [32] it has been found that the equilibrium c/a ratio is 1.64 which agrees with the mean experimental values. However for $\mathrm{t}=1.5 \mathrm{~nm}$ the c/a ratio for $\mathrm{Ni}$ has the highest value of around 1.67 and the corresponding for $\mathrm{Ru}$ is 1.63 , also the highest. For this Ni layer thickness, around $1 \mathrm{~nm}$ is of hcp structure whereas around $0.5 \mathrm{~nm}$ of fcc structure. Therefore for this sample hcp and fcc lattice mismatch would have the largest effect introducing a significant hep structure distortion on both $\mathrm{Ni}$ and $\mathrm{Ru}$. As the nominal $\mathrm{Ni}$ layer thickness increases the $\mathrm{hcp} \rightarrow \mathrm{fcc}$ transition thickness does not have much influence on hcp $\mathrm{Ni}$ and through this to the Ru layer. Also standard XRD measurements show that the texture present for thinner Ni layers is lost for layers thicker than $3 \mathrm{~nm}$.

It might be challenged that the hexagonal structure found at the $\mathrm{Ru} / \mathrm{Ni}$ interface is not hcp $\mathrm{Ni}$ but a hcp $\mathrm{RuNi}$ alloy. The $\mathrm{Ni}-\mathrm{Ru}$ system is characterized with a positive heat of formation (about $+1 \mathrm{~kJ} / \mathrm{mol}$ ) together with a small atomic size difference (the radii of $\mathrm{Ni}$ and $\mathrm{Ru}$ atom are 1.25 and 1.33 Angstrom, respectively) [40]. As Ni and Ru are immiscible at equilibrium state, there will be a strong separation between each other during multilayer deposition. The formation of non equilibrium Ni rich hcp RuNi solid state phases during magnetron sputtering has been enforced only under $200 \mathrm{keV}$ Xenon ion 
mixing [40]. The lattice constants of the $\mathrm{Ni}_{75} \mathrm{Ru}_{25}$ formed by ion mixing compound $(\mathrm{a}=0.251 \mathrm{~nm}$, $\mathrm{c}=0.404 \mathrm{~nm})$ or those determined by ab initio calculations $(\mathrm{a}=0.256 \mathrm{~nm}, \mathrm{c}=0.417 \mathrm{~nm})$ [41] are very different than those determined here $\langle a\rangle=0.275 \mathrm{~nm},\langle c\rangle=0.451 \mathrm{~nm}$. Formation of a Ni rich $(>75$ at $\%$ $\mathrm{Ni}$ ) hexagonal RuNi phase at the Ru/Ni interface cannot be excluded completely. Even in this case all the aspects discussed and conclusions reached are valid and wherever Ni (hcp) is referred would need to be replaced by Ni rich RuNi hcp phase.

The magnetic properties of the Ru/Ni multilayers have been determined by PNR and magnetization measurements. The Ru from the PNR measurements is found within the experimental accuracy $( \pm 0.02$ $\mu_{\mathrm{B}} /$ atom) to be non magnetic. Also in $\mathrm{Ni}_{80} \mathrm{Fe}_{20} / \mathrm{Ru}$ multilayers was found by PNR that the maximal polarization effect applied to the $\mathrm{Ru}$ layer is less than $0.03 \mu_{\mathrm{B}}[6]$.

The hep Ni layer on the top of the Ru is ferromagnetic and the magnetic moment per atom increases with $\mathrm{Ni}$ layer thickness and it is correlated with the increase of the magnetic moment of the fcc $\mathrm{Ni}$ layer (Table 2). The hcp Ni magnetic moment even for the thickest layer $\left(0.11 \mu_{\mathrm{B}} /\right.$ atom) is much lower than the value of $0.59 \mu_{\mathrm{B}}$ /atom obtained from ab initio calculations. However, there are divergent reports on the magnetic properties of hcp nickel nanoparticles as being nonmagnetic [42], antiferromagnetic [43] and ferromagnetic [44]. Ab initio calculations show that the energy difference between magnetic and non-magnetic hcp $\mathrm{Ni}$ is around $0.05 \mathrm{eV} /$ atom. Since the creation of the metastable hcp instead of the equilibrium fcc phase involves energy difference of this order and as it has been argued above this energy can be supplied by interfacial or impurity atoms effects, the variety of the magnetic states observed in hcp $\mathrm{Ni}$ is not surprising. It has to be mentioned that the ab initio calculations predict an hcp Ni magnetic or non-magnetic with atomic volume of around $11 \AA^{3}$ whereas the atomic volumes of our data (Table 1) are much higher. From Table (1) and (2) it is observed that as the deposited $\mathrm{Ni}$ thickness increases the hcp $\mathrm{Ni}$ atomic volume decreases and also its magnetic moment increases. Possibly at much thicker Ni layers, at which the interface effects would be minimized, the equilibrium atomic volume and magnetic moment for hep Ni might be attained. Reduction of hcp Ni magnetic constant through the incorporation of Ru atoms [45, 46] seems unlikely as it is difficult to explain the correlation of hcp Ni magnetic moment with Ni layer thickness.

Since the PNR measurements show that Ru is not magnetic and that the very thin hep Ni layer has a low magnetic moment, we may recognize that the bulk magnetization reflects the magnetic moment of the fcc Ni. Therefore from the saturation magnetization values and the Ni actual thickness and density derived from XRR, we can calculate the magnetic moment per atom in the Ni layer. These values are presented in figure 10 together with the values determined from PNR. We observe that the agreement between the macroscopically and microscopically determined values is very satisfactory taking also 
into account that the magnetic moments per atom derived from magnetization is underestimated as the actual thickness of fcc Ni is smaller than the total Ni thickness measured by XRR. The variation of fcc Ni magnetic moment versus film thickness presented in figure 10 is comparable to similar results observed in other Ni multilayer systems [8]. From figure 10 we observe that for large Ni layer thickness the magnetization tends to the bulk value of around $0.6 \mu_{\mathrm{B}} /$ atom.

Also the schema of the magnetization dependence on thickness indicates a magnetically dead layer of around $0.6 \mathrm{~nm}$ present in all the samples. This dead layer is of course the hcp Ni which from PNR is found to be around $1 \mathrm{~nm}$ for all measured samples and having a very low magnetic moment per atom (Table 2).

In summary multilayers $\mathrm{Si} / \mathrm{Ru}(9 \mathrm{~nm}) /[\mathrm{Ru}(1.5 \mathrm{~nm}) / \mathrm{Ni}(\mathrm{t} \mathrm{nm})]_{8}$ with $\mathrm{t}_{\mathrm{Ni}}$ from 0.8 to $4.5 \mathrm{~nm}$ have been fabricated by magnetron sputtering. The structure of the deposited multilayers has been determined by GIXRD and XRR and their magnetic structure by magnetometry and PNR measurements. About 1nm of $\mathrm{Ni}$ on the top of $\mathrm{Ru}$ are of hexagonal structure irrespectively of the deposited $\mathrm{Ni}$ thickness. The rest of the deposited Ni layer is of the equilibrium fcc structure. For thinner than $1.5 \mathrm{~nm} \mathrm{Ni}$ layers the Ru lattice is compressed whereas the hexagonal $\mathrm{Ni}$ lattice expanded. For thicker than $1.5 \mathrm{~nm}$ Ni layers the lattice constants and densities of the layers approach the bulk values. The hcp Ni is ferromagnetic but has a magnetic moment much lower than that expected from ab initio calculations. The magnetic moment of fcc Ni increases with Ni layer thickness tending to the bulk value. The interfacial structural incoherence offers a magnetic isolation that can be useful in preparing thick $\mathrm{Ni}$ films of low coercivity.

\section{References}

[1] Margulies D.T, Supper N., Do H., Schabes M.E., Berger A., Moser A., Rice P.M., Arnett P., Madison M.,. Lengsfield B., Rosen H.,.Tang K, Polcyn A., Fullerton E.E., 2005 J. Appl. Phys. 97, 10 N109

[2] Trindade I.G., Oliveira J., Fermento Rui,. Bessa Sousa J, Cardoso S., Freitas P.P., Raghunathan A., and. Snyder J. E, 2009 IEEE Trans. Mag 45, 168

[3]Janesky J., Rizzo N.D., Engel B.N., Tehrani S., 2004 Appl. Phys. Lett. 85, 2889

[4] P.J. Bloemen et al., Phys. Rev. B 50, 135051994

[5] Egelhoff W.F., Bonevich J., Pong P., Beauchamp C.R., Stafford G.R., Unguris J., and McMichael R.D., 2009 J. Appl. Phys. 105, 013921

[6] Hui-Chia Su, Jinn-Jer Peir, Chih-Hao Lee, Ming-Zhe Lin, Po-Tsang Wu, Huang J.C.A., Zin Tun, 2005

Physica B 357 80-83

[7] Ming-Zhe Lin, Hui-Chia Su, Chih-Hao Lee, J.C.A. Huang, 2007 Surf. Sci. 601 5707-5711

[8] Vaz C.A.F., Bland J.A.C., Lauhoff G., 2008 Rep. Prog. Phys. 71056501

[9] De Santis M., De Andres A., Raoux D., Maurer M., Ravet M.F., Piecuch M., 1992 Phys. Rev. B. 4615465

[10] LEPTOS ver. 6.02 by Bruker-AXS GmbH 2002-2008

[11] http://www-llb.cea.fr/prism/programs/simulreflec/simulreflec.html, version 1.9

[12] Wroński S., Wierzbanowski K., Baczmański A, Lodini A., Braham Ch.and Seiler W., June 2009, Powder

Diffraction Suppl. 24 S1 
[13] Raghavendra Reddy V, Ajay Gupta, Anil Gome, Wolfram Leitenberger and Pietsch U; J. Phys.: Condens. Matter 212009186002.

[14] The database of the Joint Committee on Powder Diffraction Standards JCPDS of the International Centre for Diffraction Data ICDD, includes the powder diffraction files PDF, no 45-1027 for hexagonal Ni and no 700274 for hexagonal Ru.

[15] Milton Ohring in "Materials Science of Thin Films" (Second Edition) 2002 Elsevier Inc.

ISBN: 978-0-12-524975-1, Chapter 8.

[16] Burgler D.E., Grunberg P., Demokritov S.O.,. Johnson M.T, 2001 Handbook of Magnetic Materials, Vol.13, Chapter 1, Ed. K.H.J. Buschow, Elsevier Science

[17] Bloemen P.J.H., Kesteren H.W.,. Swagten H.J.M,. de Jonge W.J.M, 1994 Phys. Rev. B 50 13505-13514

[18] Tiusan C., Hehn M.; and Ounadjela K., 2002, Eur. Phys. J. B 26, 431.

[19] Tutovan V., Velican N., 1973 Thin Solid Films, 15, 31-37.

[20] Yutaka Sugita, Hideo Fujiwara, Takashi Sato, 1967, Appl. Phys. Lett. 10229.

[21] Holz A., Kronmuller H., 1969 Phys. Stat. Solid. 31, 787

[22]Giovanni C., Giorgio C., Stefano E., Renzo G., Maurizio L., 1988 Mater. Lett. 747

[23] Mia Y., Yuan D., Liu Y., Zhang J., Xiao Y.; 2005 Mater. Chem. Phys. 89, 359-361

[24]Tzitzios V., Basina G., Gjoka M., Alexandrakis V., Georgakilas V., Niarchos D., Boukos N. and Petridis D., 2006 Nanotechnology 17 3750-3755

[25] Rodriguez-Gonzalez V., Marceau E., Beaunier P., Che M., Train C., 2007 J. Solid State Chem. 180 22-30

[26]Gong J., Wang L.L., Liu Y., Yang J.H., Zong Z.G., J. of Alloys and Compd 4572008 6-9

[27] Mourdikoudis S., Simeonidis K., Vilalta-Clemente A., Tuna F., Tsiaoussis I., Angelakeris M.,

. Dendrinou-Samara C, Kalogirou O.; 2009 J. Magn. Magn. Mat. 321 2723-2728

[28] Yuanzhu Mi, Dingsheng Yuan, Yingliang Liu, Jingxian Zhang, Yong Xiao; 2005 Mater. Chem.Physics 89 359-361

[29] Xiaohua Luo, Yuanzhi Chen, Guang-Hui Yue, Dong-Liang Peng, Xuetao Luo, 2009 , J. Alloys Compd. 476 864

[30] Geng K.W., He T., Yang G.H., Pan F., 2004 J. Mag. Mag. Mater. 284 26-34

[31] Albrecht M., Maret M. , Köhler J., Gilles B., Poinsot R., Hazemann J.L., Tonnerre J.M., Teodorescu C., and Bucher E., 2000 Phys. Rev. Lett. 855344

[32] He X., L. Kong T., and Liu B.X., 2005 J. Appl. Phys. 97106107

[33] Illy S., Tillement O., Machizaud F., Dubois J.M., Massicot F., Fort Y., Ghanbaja J., 1999 Philos. Mag. 79 1021

[34] Tian W., Sun H.P., Pan X.Q., Yu J.H., Yeadon M., and Boothroy C.B.,. Feng Y.P, Lukaszew R.A., Clarke R.; 2005 Appl. Phys. Lett. 86, 131915

[35] Wright J.G., Goddard J., 1965 Philos. Mag. 11, 485

[36] Poulopoulos P., Kapaklis V., Politis C., Schweiss P., Fuchs D., 2006, Journal of Nanoscience and Nanotechnology, Vol.6, 3867-3870

[37]Saint-Lager M.C., Raoux D., Brunel M., Piecuch M., Elkffim E. and Lauriat J.P, 1995, Phys. Rev. B 512446

[38] Mary Beth Stearns, 1988 Phys. Rev. B 388109

[39] Ming Xu, Guangming Luo, Chunling Chai, Zhenhong Mai, Wuyan Lai, Zhonghua Wu, Dewu Wang, 2000 J Cryst Growth 212291

[40] Li X.Y., Li Z.F., Liu B.X., 2002 J. Alloys Compd. 334167

[41] He X., Kong L.T., Li J.H., Li X.Y., Liu B.X., 2006 Acta Mater 54 3375-3381

[42] Chinnasamy C N, Jeyadevan B, Shinoda K, Tohji K, Narayanasamy A, Sato K and Hisano S, 2005 J. Appl. Phys. 97 10J309

[43] Jeon Y T, Moon J Y, Lee G H, Park J and Chang Y, 2006 J. Phys. Chem. B 110, 1187

[44] Han M, Liu Q, He J H, Song Y, Xu Z and Zhu J M, 2007 Adv. Mater. 191096

[45]Parette G., Kajzar F, 1979, J. Phys. F: Metal Phys. 9, 1867

[46]Madhav Rao L., Chakravarthy R., Jirak Z., and. Satya Murthy N.S; 1978 Phys. Rev. B 18, 6275-6282 


\section{Tables}

Table 1. Structural parameters of the series of multilayers $\mathrm{Si} / \mathrm{Ru}(9 \mathrm{~nm}) /[\mathrm{Ru}(1.5 \mathrm{~nm}) / \mathrm{Ni}(\mathrm{t})] \times 8$ obtained from GIXRD and XRR data.

\begin{tabular}{|c|c|c|c|c|c|c|c|c|}
\hline \multirow[b]{2}{*}{$\begin{array}{l}\mathbf{t}_{\mathrm{Ni}} \\
(\mathbf{n m})\end{array}$} & \multirow[b]{2}{*}{ Layer } & \multicolumn{4}{|c|}{ GIXRD } & \multicolumn{3}{|c|}{ XRR } \\
\hline & & c (nm) & a (nm) & $\mathbf{c} / \mathbf{a}$ & $\begin{array}{c}\text { Atomic } \\
\text { volume } \\
\left(\mathbf{n m}^{3}\right)\end{array}$ & $\begin{array}{c}\text { Thickness } \\
\text { (nm) }\end{array}$ & $\begin{array}{c}\text { Roughness } \\
\text { (nm) }\end{array}$ & $\begin{array}{c}\text { Density, d } \\
\left(\mathrm{g} / \mathrm{cm}^{3}\right)\end{array}$ \\
\hline \multirow[t]{2}{*}{4.5} & $\mathrm{Ru}$ & 0.4265 & 0.2647 & 1.611 & 0.01294 & 1.80 & 0.46 & 12.36 \\
\hline & $\mathrm{Ni}$ & 0.4404 & 0.2686 & 1.640 & 0.01376 & 4.37 & 0.53 & 8.91 \\
\hline \multirow[t]{2}{*}{3.0} & $\mathrm{Ru}$ & 0.4243 & 0.2608 & 1.627 & 0.0125 & 1.52 & 0.38 & 12.08 \\
\hline & $\mathrm{Ni}$ & 0.4324 & 0.2672 & 1.618 & 0.01337 & 3.28 & 0.70 & 8.91 \\
\hline \multirow[t]{2}{*}{1.5} & $\mathrm{Ru}$ & 0.4187 & 0.257 & 1.629 & 0.01197 & 1.77 & 0.56 & 12.37 \\
\hline & $\mathrm{Ni}$ & 0.4589 & 0.2747 & 1.671 & 0.01499 & 1.45 & 0.60 & 7.75 \\
\hline \multirow[t]{2}{*}{1.0} & $\mathrm{Ru}$ & 0.4217 & 0.2615 & 1.613 & 0.01249 & 1.93 & 0.48 & 11.50 \\
\hline & $\mathrm{Ni}$ & 0.461 & 0.282 & 1.635 & 0.01587 & 0.94 & 0.55 & 8.91 \\
\hline \multirow[t]{2}{*}{0.75} & $\mathrm{Ru}$ & 0.4221 & 0.2626 & 1.607 & 0.0126 & 2.06 & 0.71 & 11.80 \\
\hline & $\mathrm{Ni}$ & 0.4628 & 0.2837 & 1.631 & 0.01613 & 0.65 & 0.53 & 8.19 \\
\hline 0 & $\mathrm{Ru}$ & 0.427 & 0.2689 & 1.588 & 0.01367 & - & - & - \\
\hline \multirow[t]{3}{*}{ bulk } & $\mathrm{Ru}$ & 0.42811 & 0.27058 & 1.582 & 0.01322 & - & - & 12.36 \\
\hline & Ni hex & 0.4343 & 0.26515 & 1.638 & 0.01357 & - & - & 7.372 \\
\hline & Ni cubic & & 0.35238 & & 0.01094 & & & 8.911 \\
\hline
\end{tabular}


Table 2. Least square determined parameters from PNR data employing model B.

\begin{tabular}{lcccc}
\hline & $\begin{array}{c}\text { Layered } \\
\text { structure }\end{array}$ & $\begin{array}{c}\text { Thickness } \\
(\mathrm{nm})\end{array}$ & $\begin{array}{c}\text { Moment } \\
\left(\mu_{\mathrm{B}}\right)\end{array}$ & $\begin{array}{c}\text { Roughness } \\
(\mathrm{nm})\end{array}$ \\
\hline & $\mathrm{Ru}$ & 1.55 & 0 & 0.82 \\
{$[\mathrm{Ru}(1.5 \mathrm{~nm}) / \mathrm{Ni}(4.5 \mathrm{~nm})] \times 8$} & $\mathrm{Ni} 1$ & 0.96 & $0.11 \pm 0.04$ & 0.57 \\
& $\mathrm{Ni} 2$ & 3.85 & $0.61 \pm 0.02$ & 0.79 \\
\hline$[\mathrm{Ru}(1.5 \mathrm{~nm}) / \mathrm{Ni}(3.0 \mathrm{~nm})] \times 8$ & $\mathrm{Ru}$ & 1.52 & 0 & 0.99 \\
& $\mathrm{Ni} 1$ & 1.22 & $0.08 \pm 0.04$ & 0.22 \\
& $\mathrm{Ni} 2$ & 2.12 & $0.56 \pm 0.02$ & 0.50 \\
\hline$[\mathrm{Ru}(1.5 \mathrm{~nm}) / \mathrm{Ni}(1.5 \mathrm{~nm})] \times 8$ & $\mathrm{Ru}$ & 1.89 & 0 & 1.03 \\
& $\mathrm{Ni} 1$ & 0.78 & $0.04 \pm 0.04$ & 0.30 \\
& $\mathrm{Ni} 2$ & 0.59 & $0.40 \pm 0.02$ & 0.45 \\
\hline
\end{tabular}




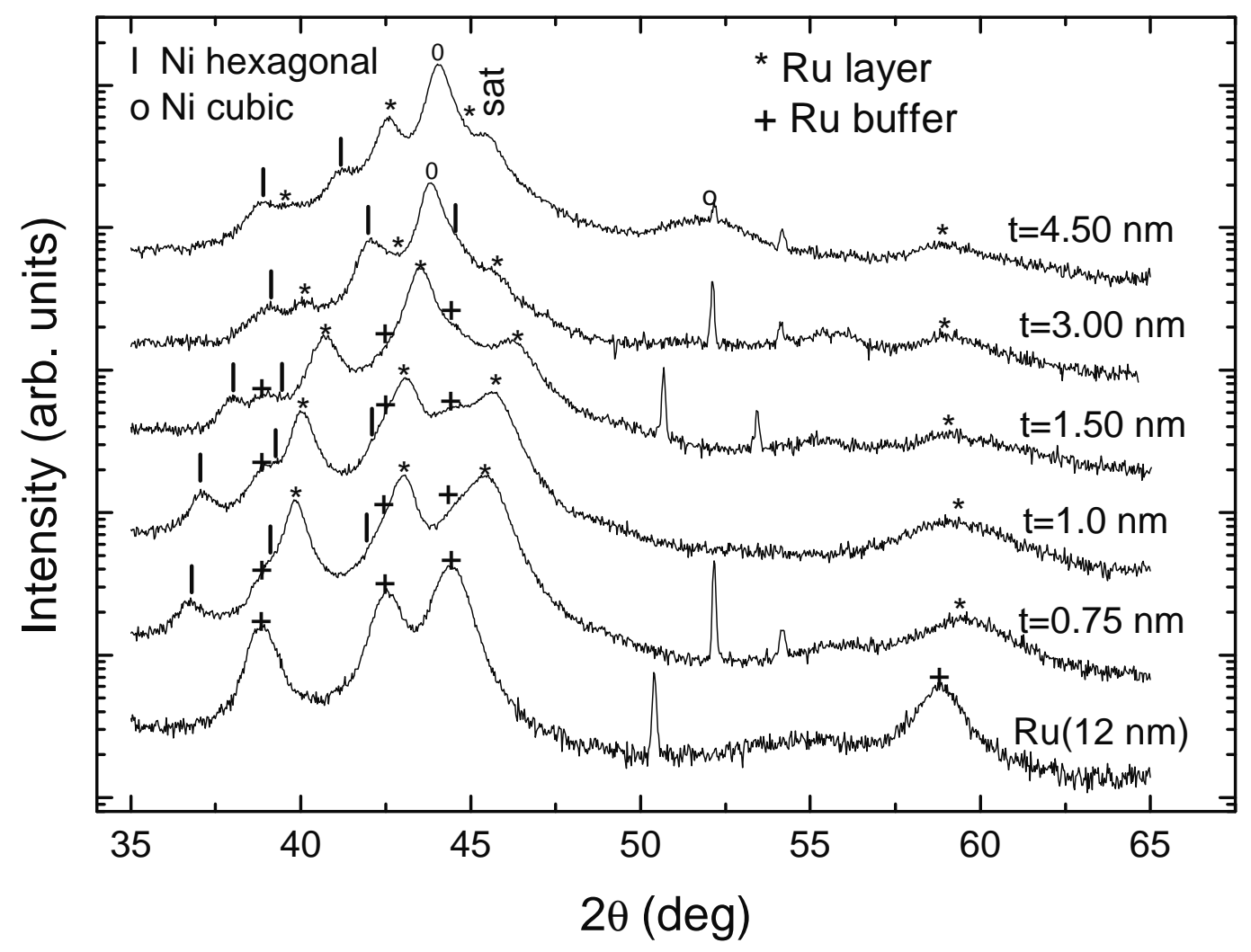

Figure 1. Grazing incidence diffraction patterns for different $\mathrm{Si} / \mathrm{Ru}(9 \mathrm{~nm}) /[\mathrm{Ru}(1.5 \mathrm{~nm}) / \mathrm{Ni}(\mathrm{t} \mathrm{nm})]_{8}$ multilayers. The bottom diffractogram is from a single Ru layer of $12 \mathrm{~nm}$ thickness, + : Ru buffer layer. *: Ru layer in multilayer structure, o: Ni cubic $\mid:$ Ni hexagonal. The diffraction patterns of the different samples are displaced along the y-axis (intensity) for clarity. 


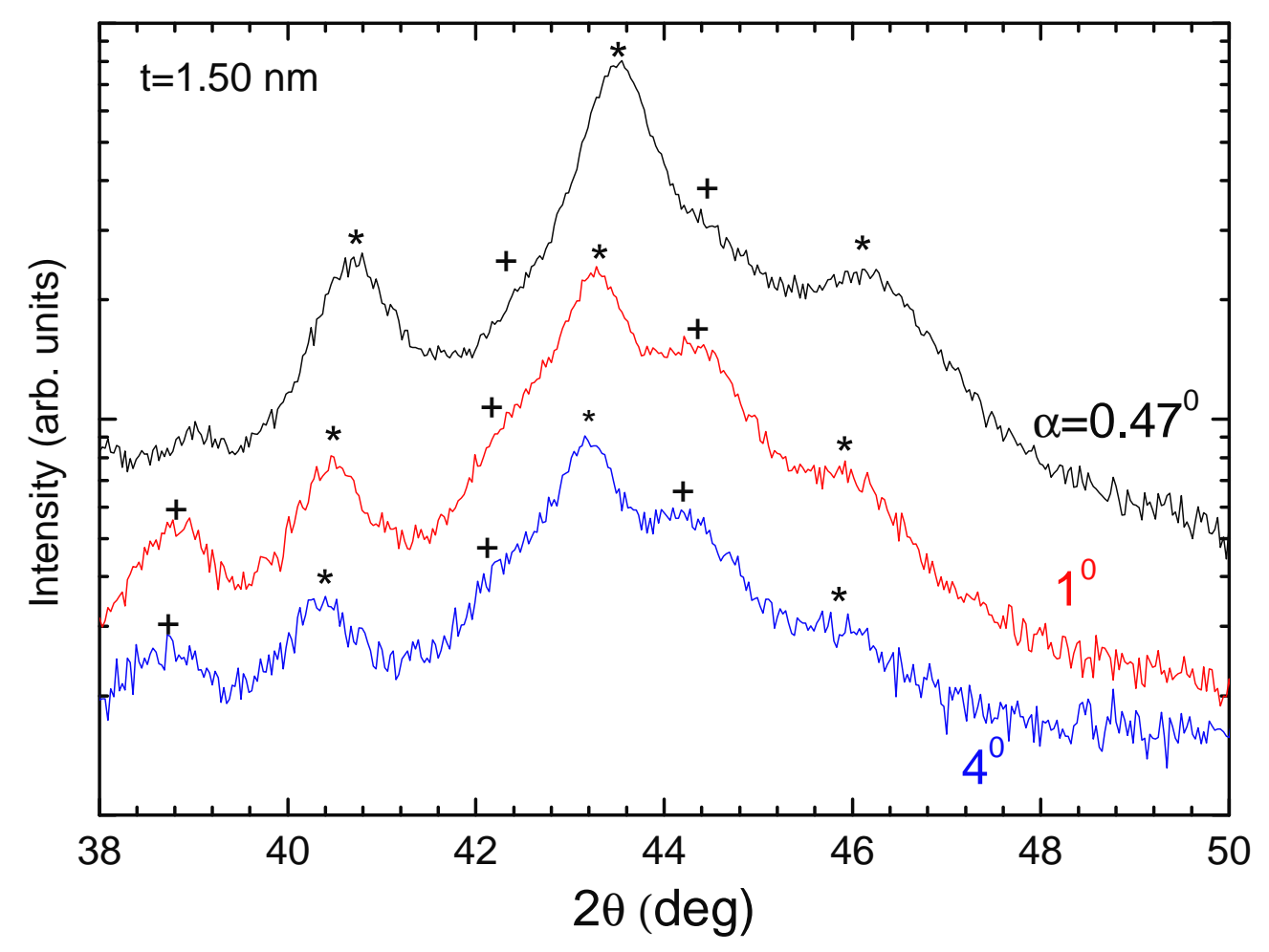

Figure 2. Grazing incidence $X$-ray diffraction patterns from $[\mathrm{Ru}(1.5 \mathrm{~nm}) / \mathrm{Ni}(1.5 \mathrm{~nm})] \times 8$ multilayer for different values of incidence angle $\alpha .+$ : Ru buffer * : Ru layer in multilayer structure. The different diffraction patterns are displaced along the y-axis (intensity) for clarity. 


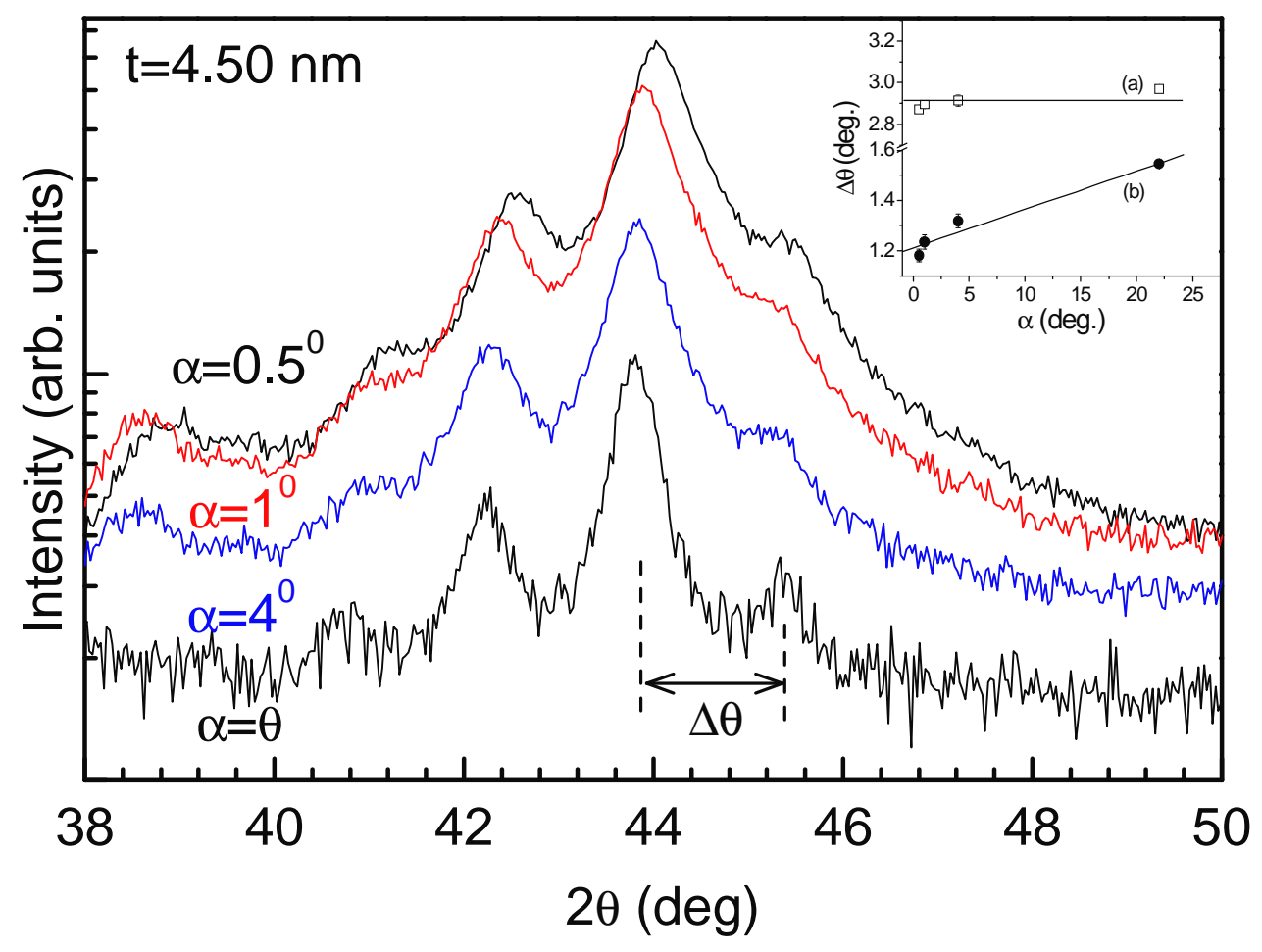

Figure 3. Comparison of grazing incidence $X$-ray diffraction patterns of $\mathrm{Ru}(1.5 \mathrm{~nm}) / \mathrm{Ni}(4.5 \mathrm{~nm})] \times 8$ for different values of incidence angle $\alpha$.The conventional $\theta-2 \theta$ scan is indicated as $\alpha=\theta$. Inset ( $\square$, a): Separation between the Bragg peak at $\sim 44^{0}$ and the peak at $\sim 41^{0}$ as a function of the incidence angle $\alpha ;(\bullet, \mathrm{b})$ : Separation between the Bragg peak at $\sim 44^{0}$ and the peak at $\sim 45.5^{\circ}$ as a function of the incidence angle $\alpha$. 


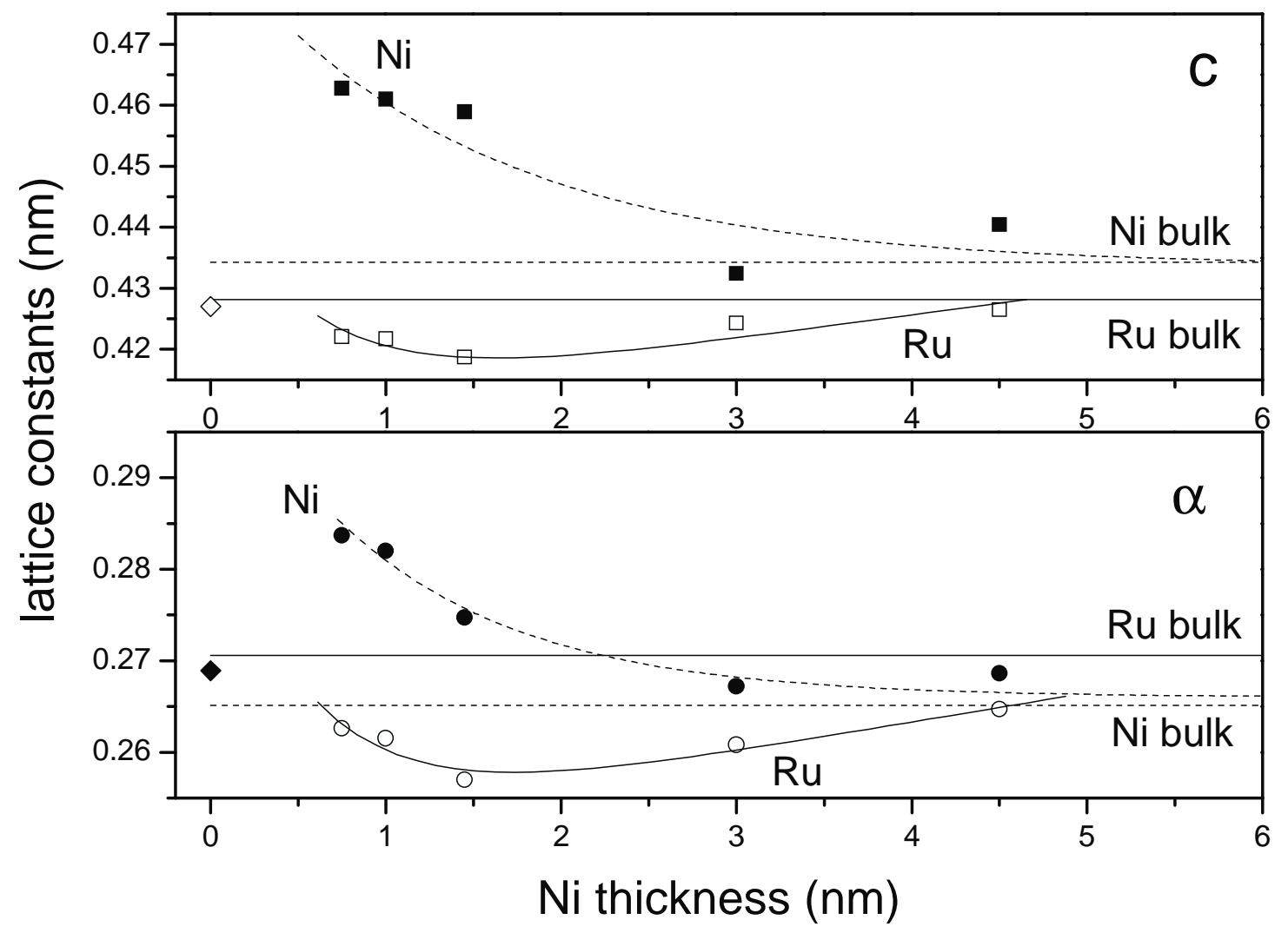

Figure 4. The lattice constants of hexagonal $\mathrm{Ni}$ (a-axis $\bullet$, c-axis $\mathbf{m}$ ), and $\mathrm{Ru}$ (a-axis $\circ$, c-axis $\square$ ) versus $\mathrm{Ni}$ layer nominal thickness, in Ru/Ni multilayers. Solid lines are guide to the eye. At zero Ni thickness the values of the Ru single layer are presented with the symbols $\bullet$ : a-axis and $\diamond$ : c-axis. The values of the bulk lattice constants, according to powder diffraction files (PDF) 45-1027 for hexagonal Ni and PDF: 70-0274 for $\mathrm{Ru}$, are indicated by dotted and solid lines. 


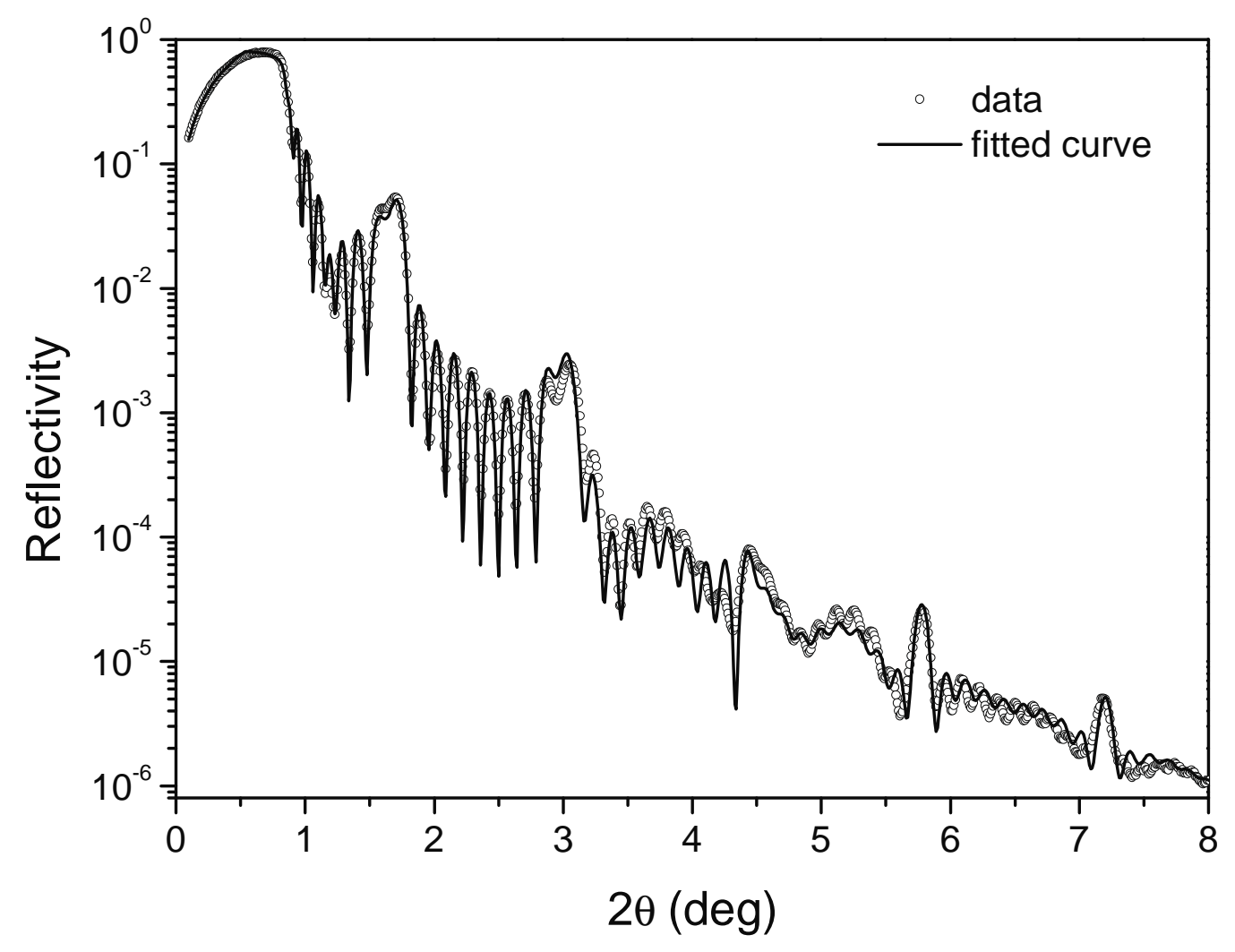

Figure 5. X-ray reflectivity data from the sample $[\mathrm{Ru}(1.5 \mathrm{~nm}) / \mathrm{Ni}(4.5 \mathrm{~nm})] \times 8$. Solid line: least square fit to the data. 


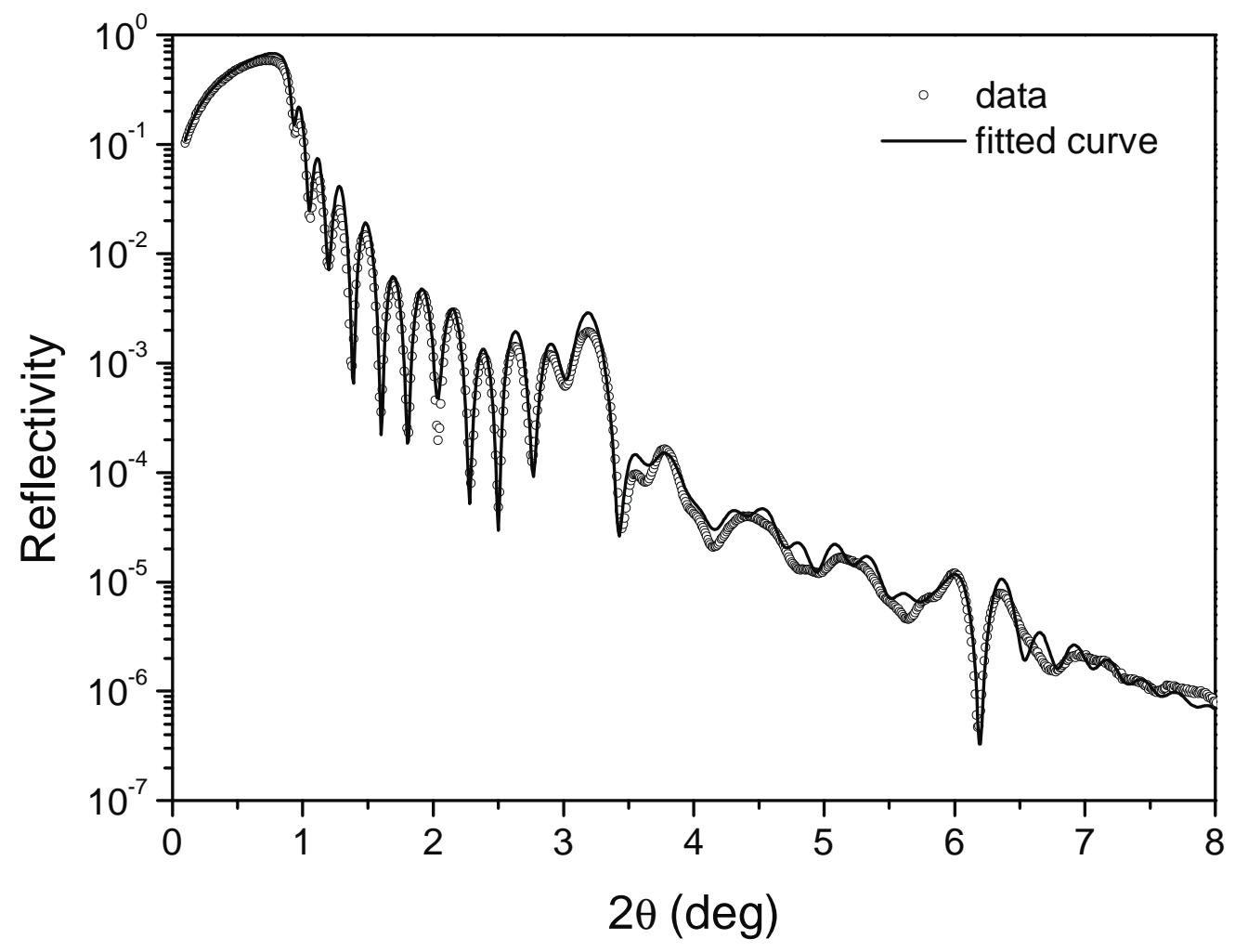

Figure 6. X-ray reflectivity data from the sample $[\mathrm{Ru}(1.5 \mathrm{~nm}) / \mathrm{Ni}(1.0 \mathrm{~nm})] \times 8$. Solid line: least square fit to the data. 


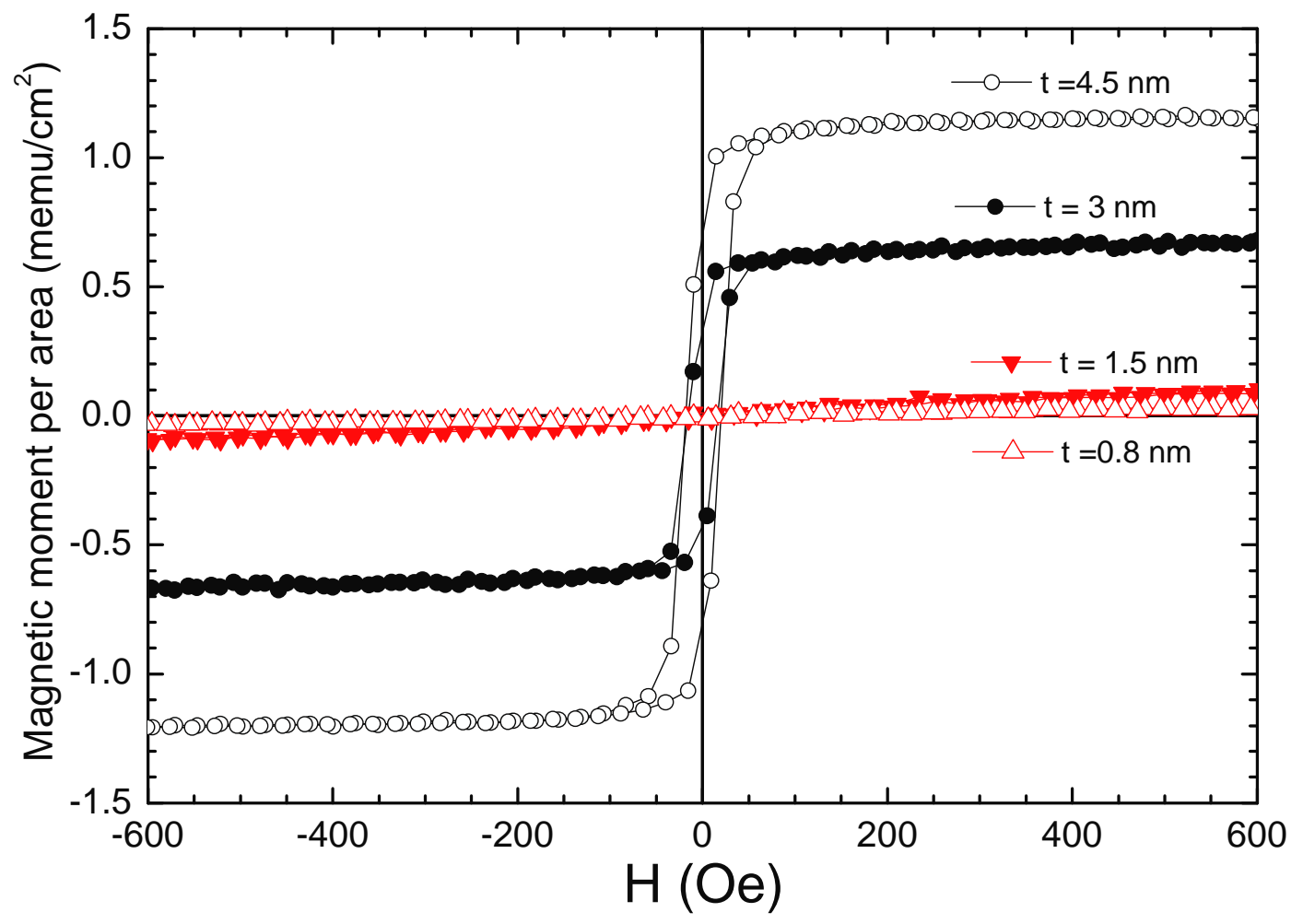

Figure 7. Hysteresis loops of $\mathrm{Si} / \mathrm{Ru}(9 \mathrm{~nm}) /[\mathrm{Ru}(1.5 \mathrm{~nm}) / \mathrm{Ni}(\mathrm{t} \mathrm{nm})]_{8}$ multilayers with $\mathrm{t}=4.5 \mathrm{~nm}$ (open circles), $\mathrm{t}=3 \mathrm{~nm}$ (solid circles), $\mathrm{t}=1.5 \mathrm{~nm}$ (open triangles), $\mathrm{t}=0.8 \mathrm{~nm}$ (solid triangles). The measurements were performed with the applied field in the film plane. 


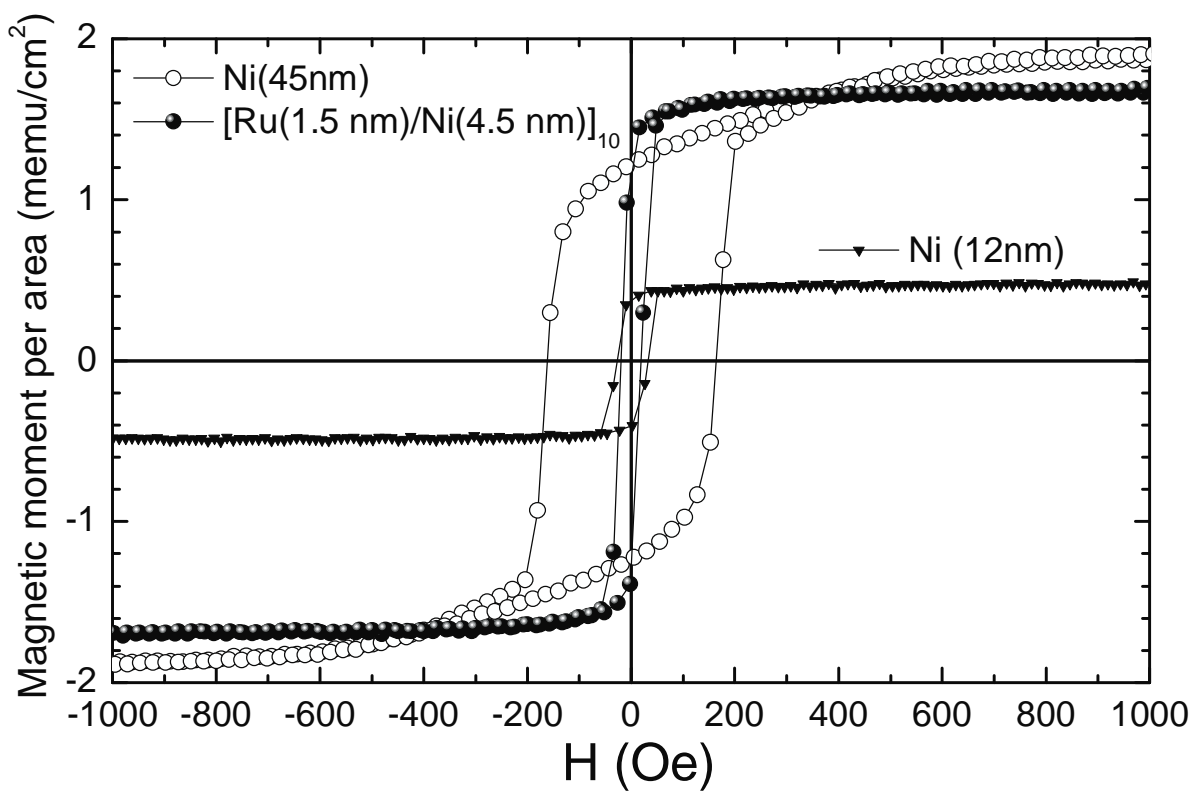

Figure 8. Comparison of Hysteresis loops of a $45 \mathrm{~nm}$ Ni single layer (open circles), a $12 \mathrm{~nm}$ Ni single layer (solid triangles) and a $[\mathrm{Ru}(1.5 \mathrm{~nm}) / \mathrm{Ni}(4.5 \mathrm{~nm})]_{10}$ multilayer (solid circles). The measurements were performed with the applied field in the film plane. 


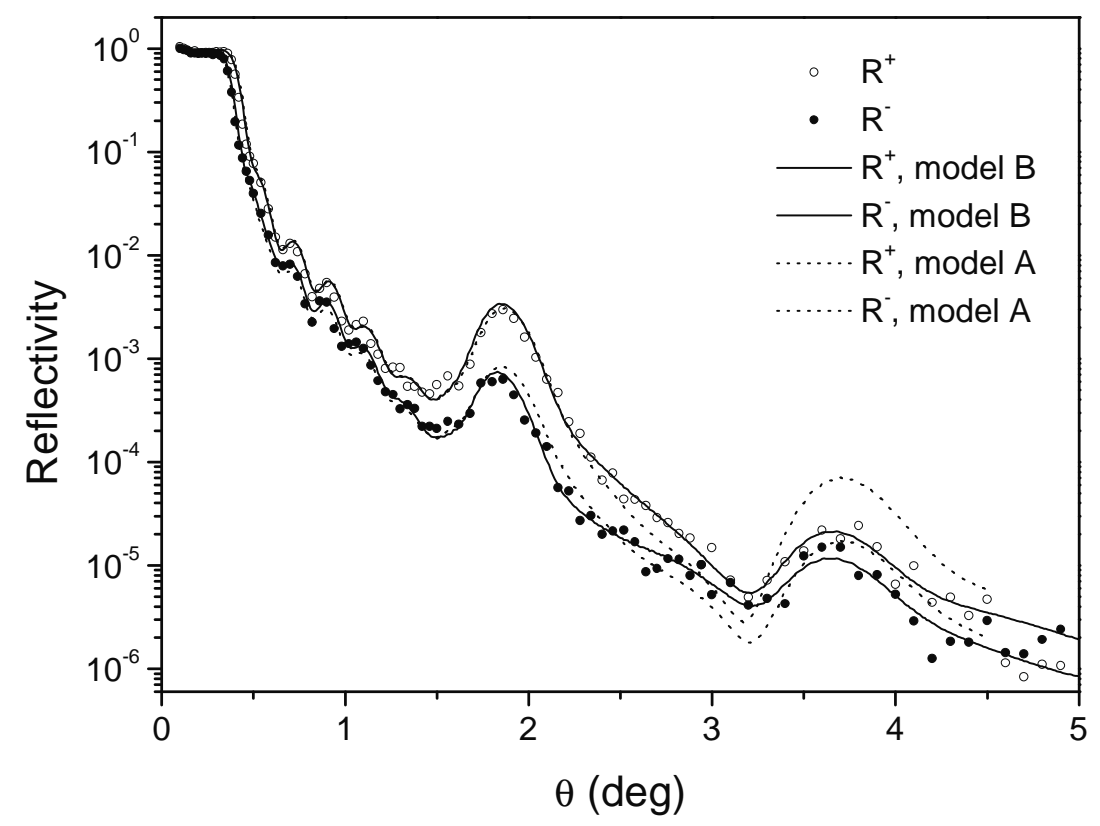

Figure 9. PNR data for the sample $[\mathrm{Ru}(1.5 \mathrm{~nm}) / \mathrm{Ni}(4.5 \mathrm{~nm})] \times 8$. Experimental data: $\circ$ for $\mathrm{R}+($ spin up $)$ and $\bullet$ for R- (spin down). Dashed line: model A. Solid line: model B. 


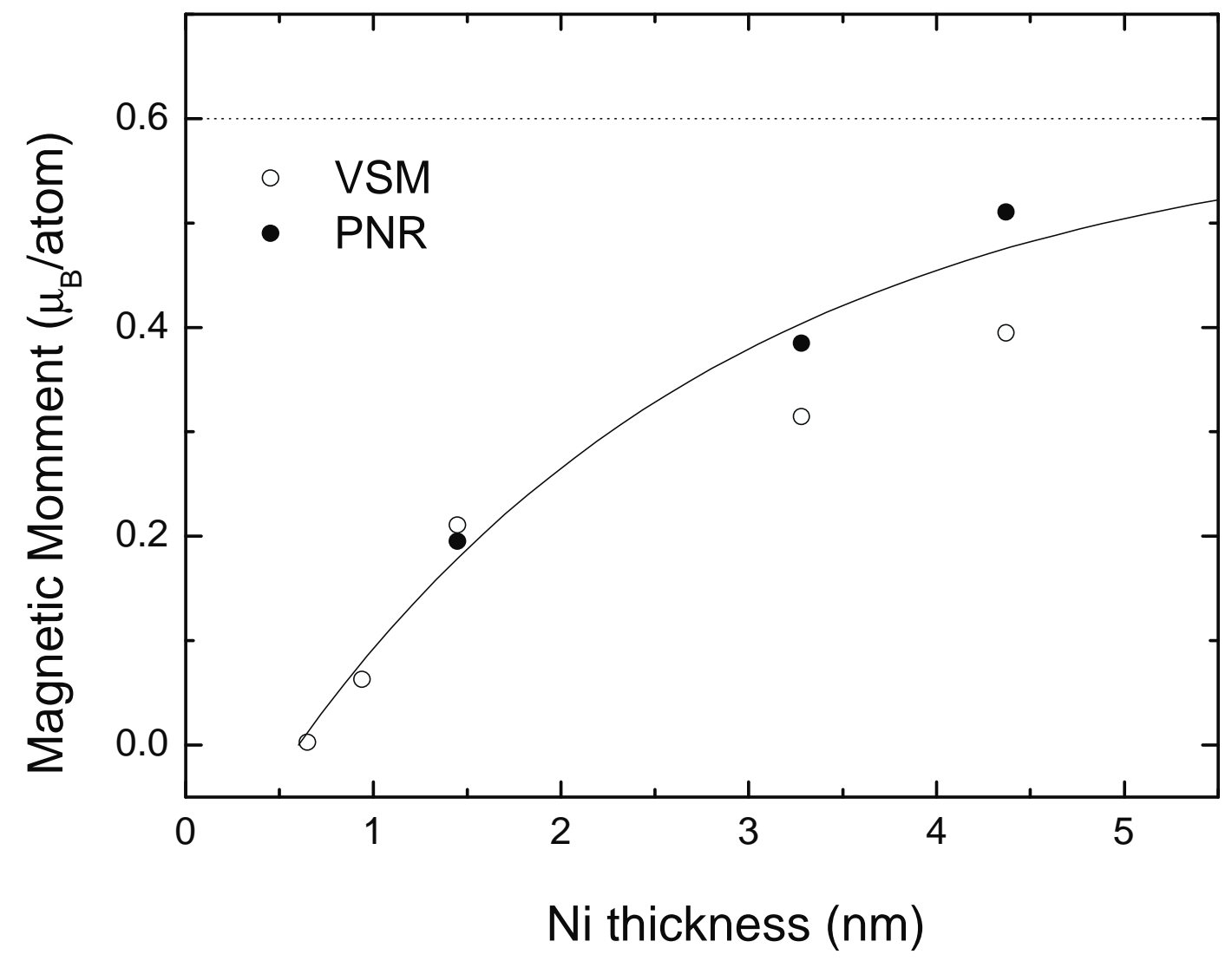

Figure 10. Fcc Ni layer magnetic moment per atom versus actual Ni layer thickness, $t_{\mathrm{Ni}}$, obtained by XRR•: data obtained from PNR measurements, O: data obtained from magnetization measurements and reduced to a $\mu_{\mathrm{B}}$./atom using the Ni layer thickness and density obtained by XRR (Table 1 ).

Continuous line the equation $y\left(\mu_{\mathrm{B}} /\right.$ atom $)=0.6\left[1-\exp \left(-\frac{t_{\mathrm{Ni}}(\mathrm{nm})}{2.4}\right)\right]$ 


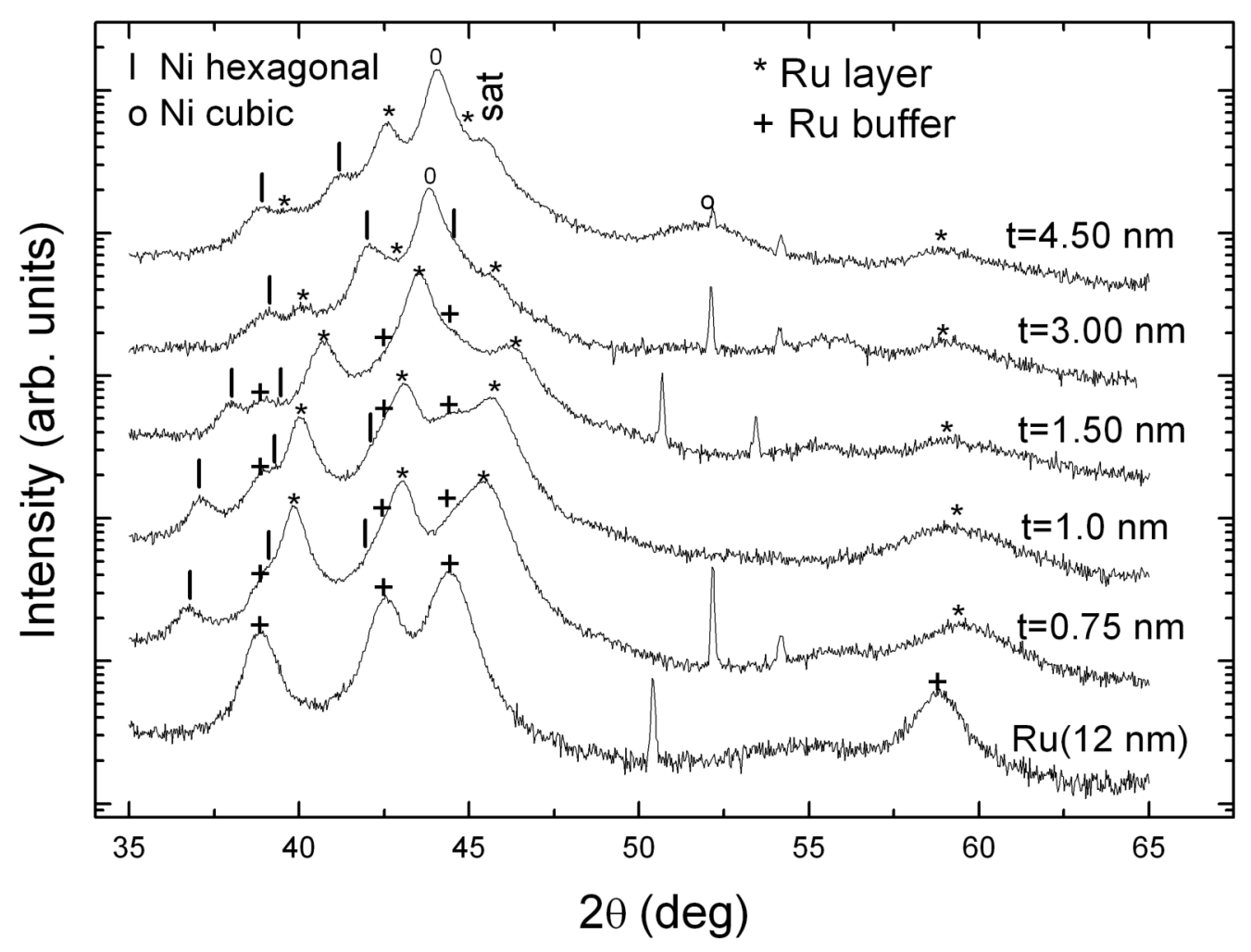

Figure 01 (Fig1.jpg) 


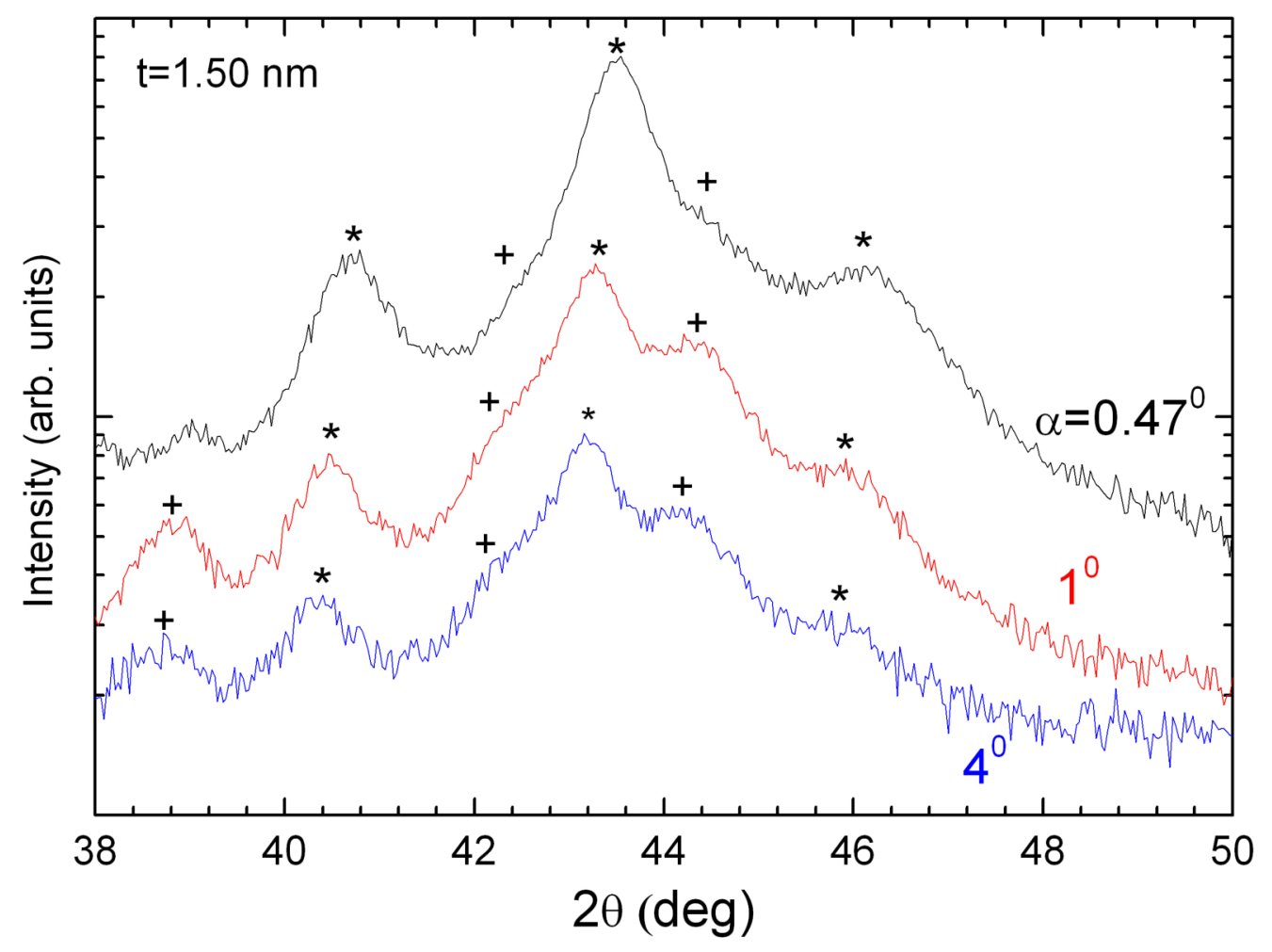

Figure 02 (Fig2.jpg) 


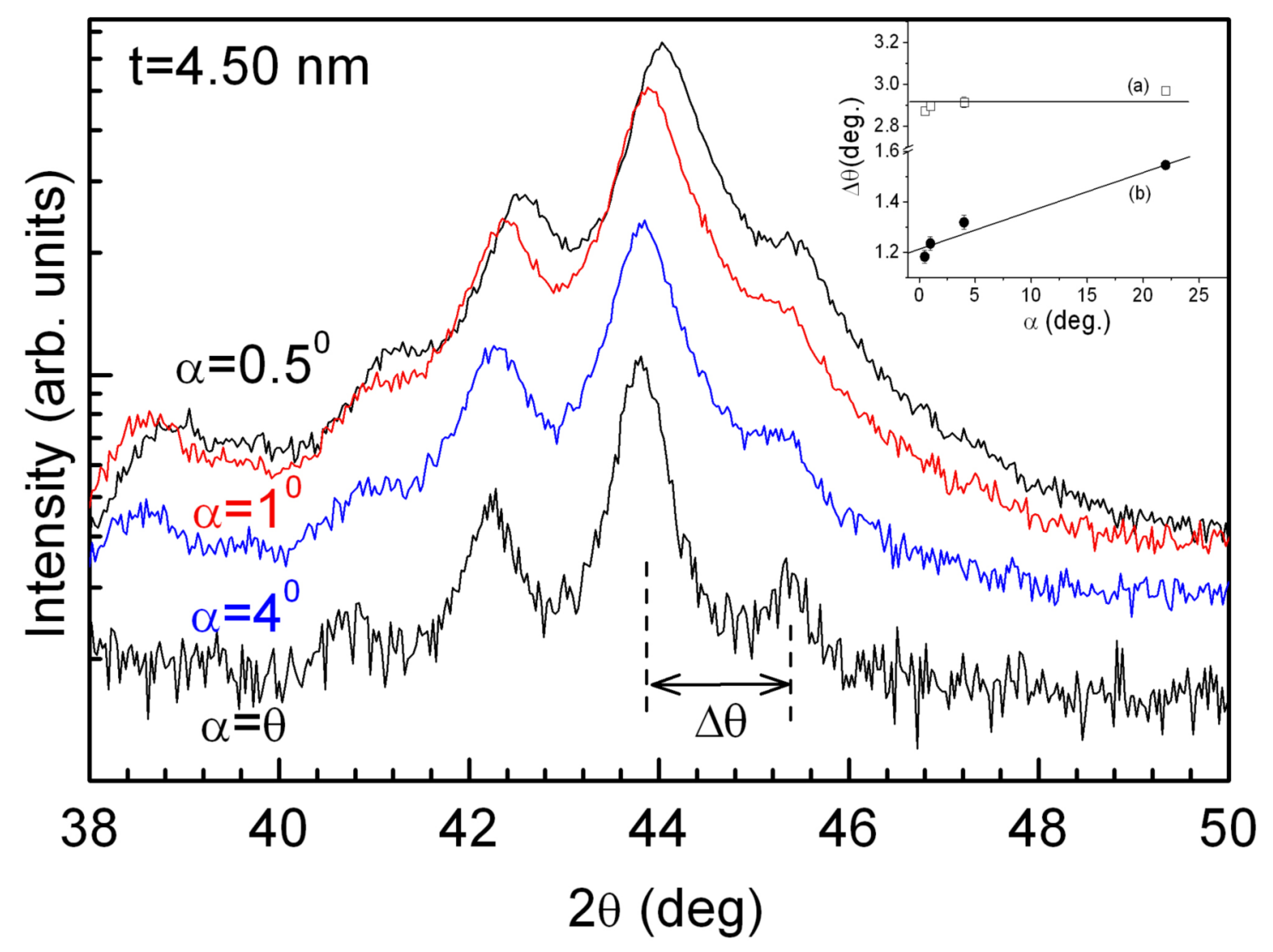

Figure 03 (Fig3.jpg) 


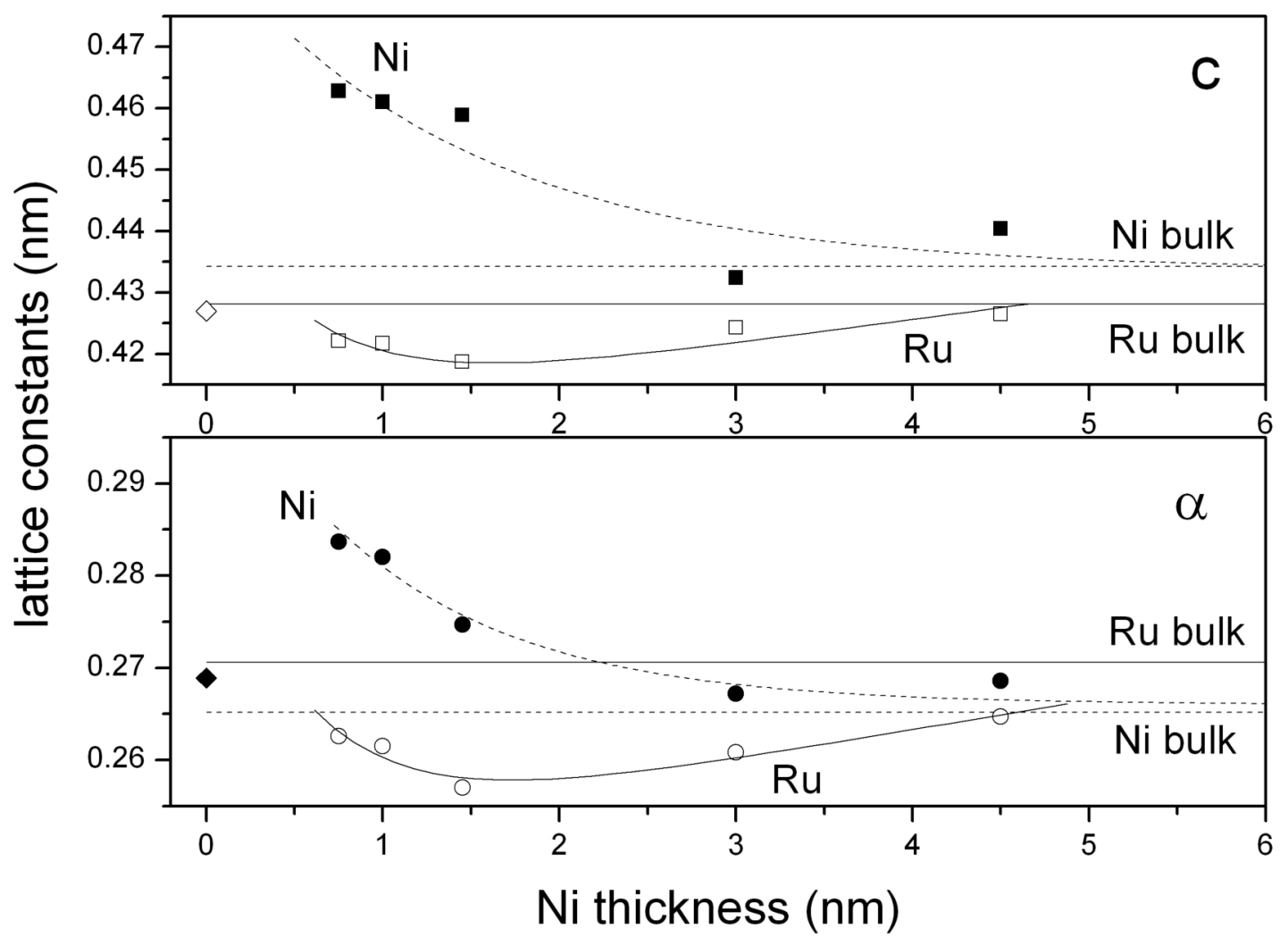

Figure 04 (Fig4.jpg) 


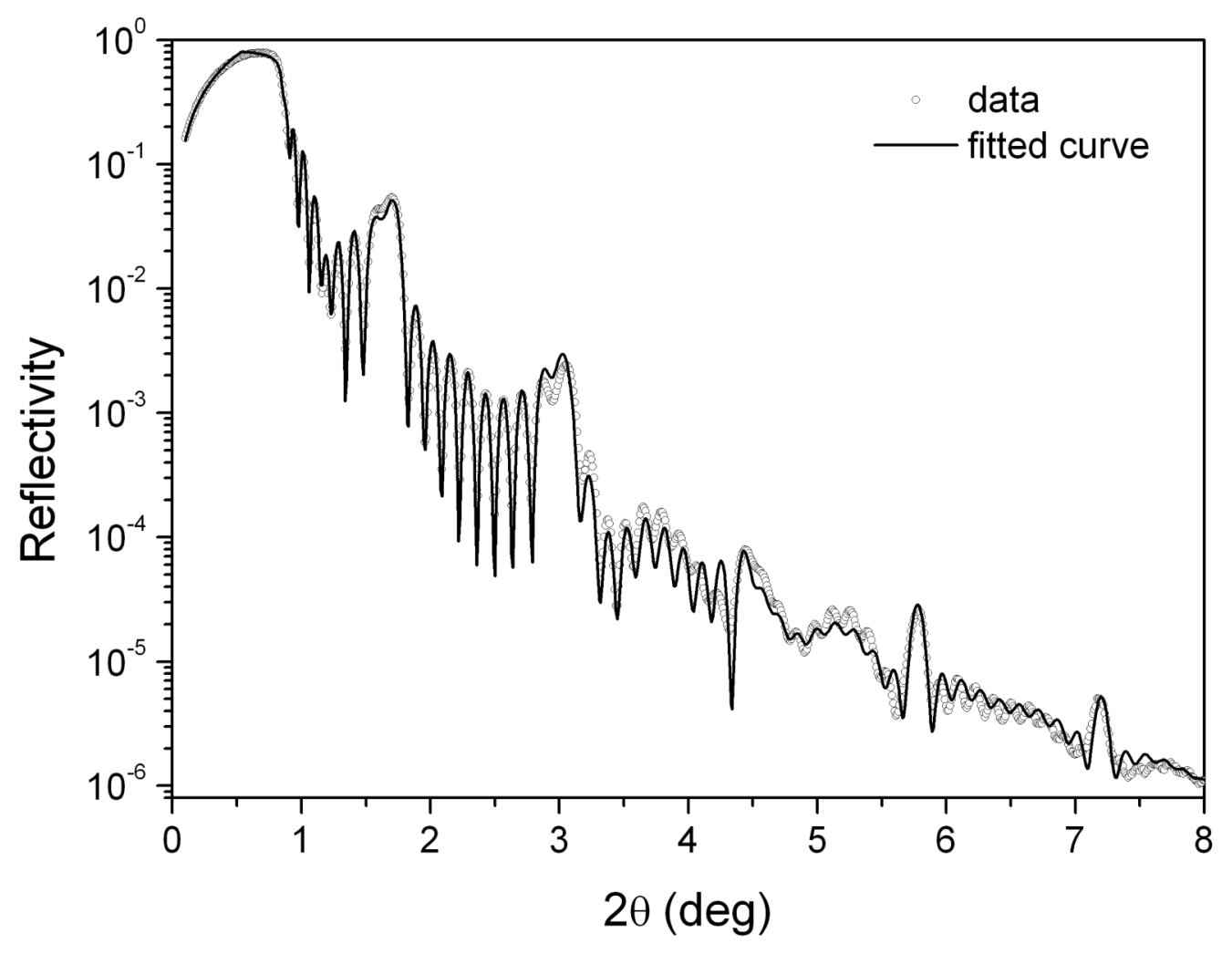

Figure 05 (Fig5.jpg) 


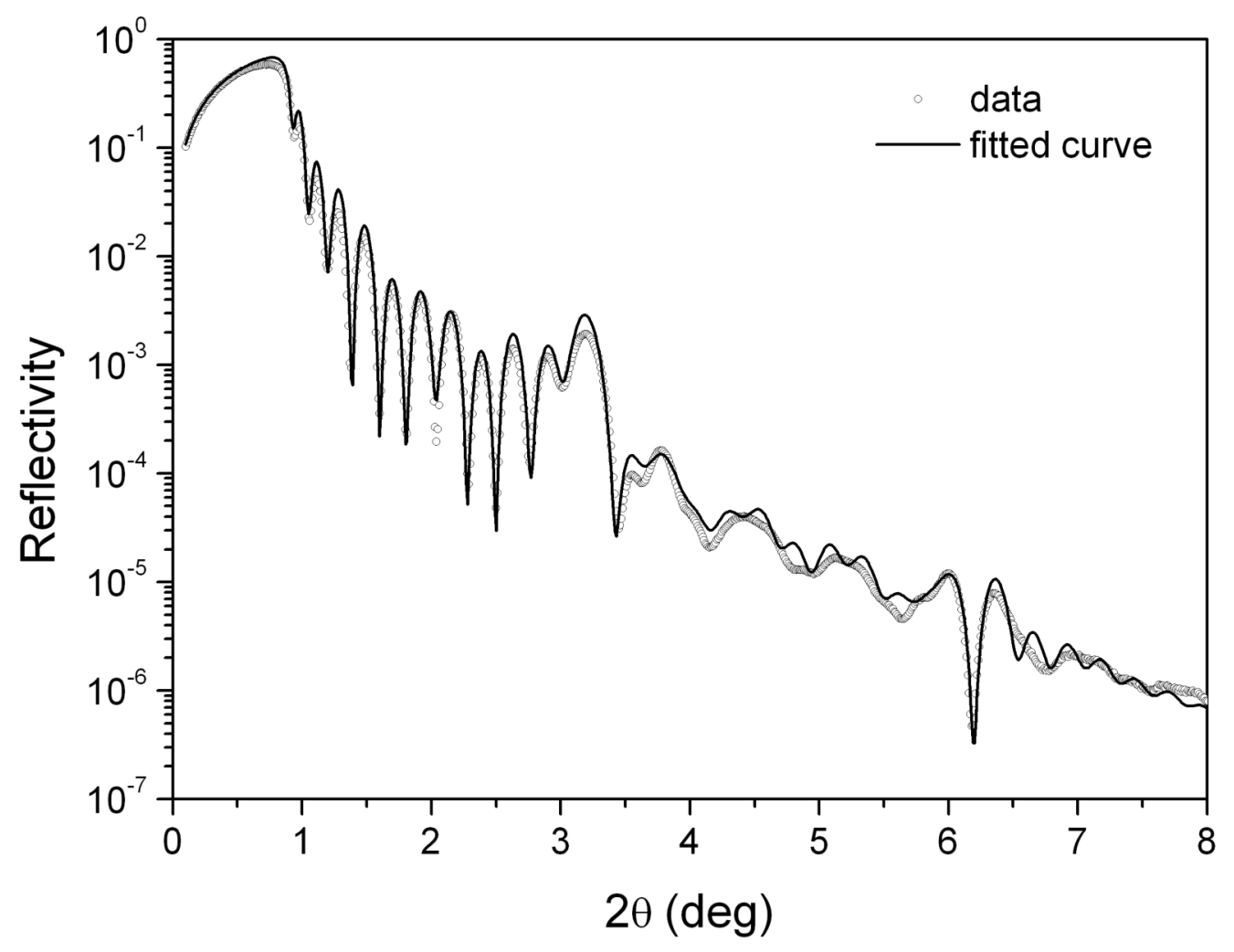

Figure 06 (Fig6.jpg) 


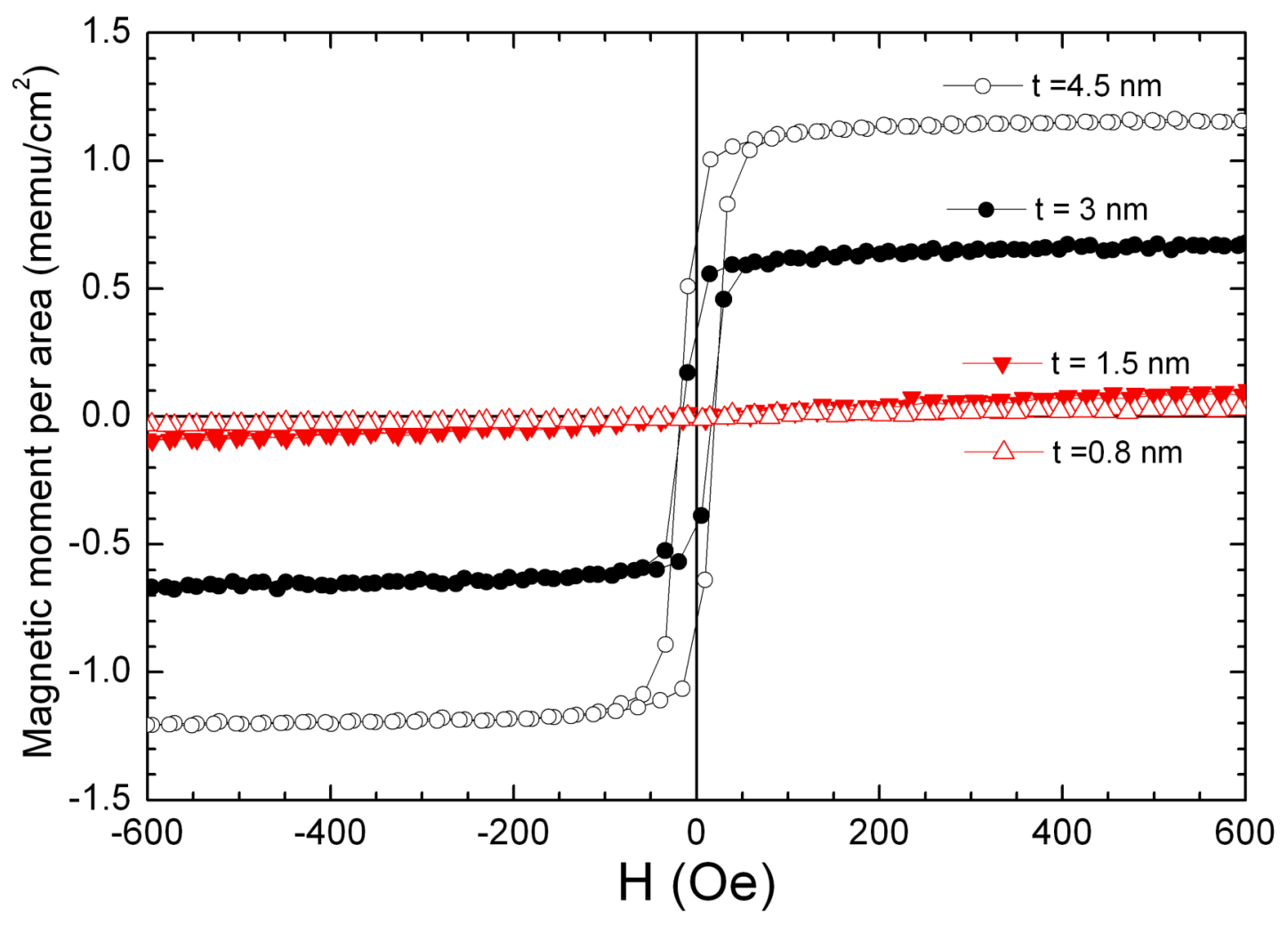

Figure 07 (Fig7.jpg) 


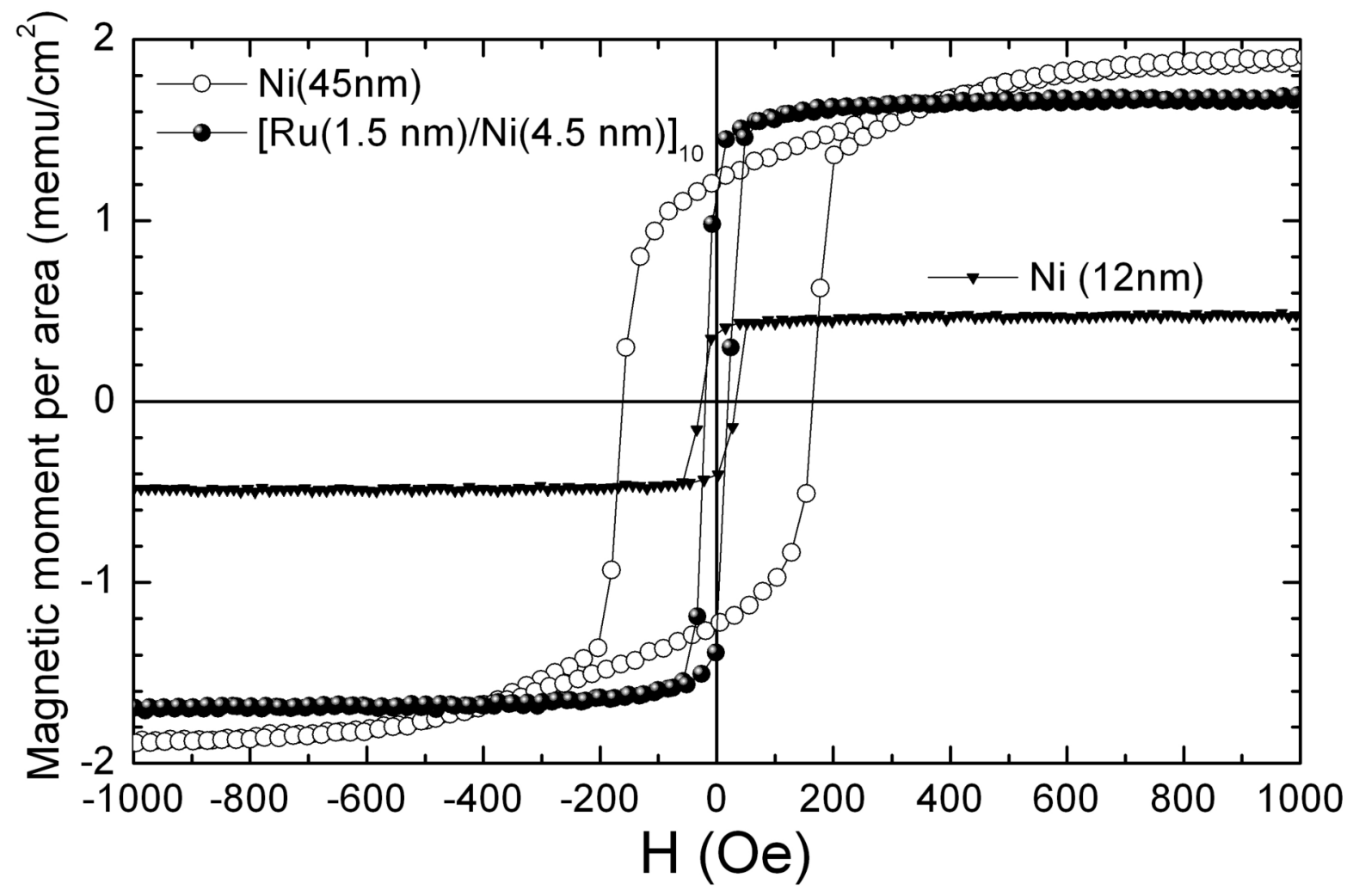

Figure 08 (Fig8.jpg) 


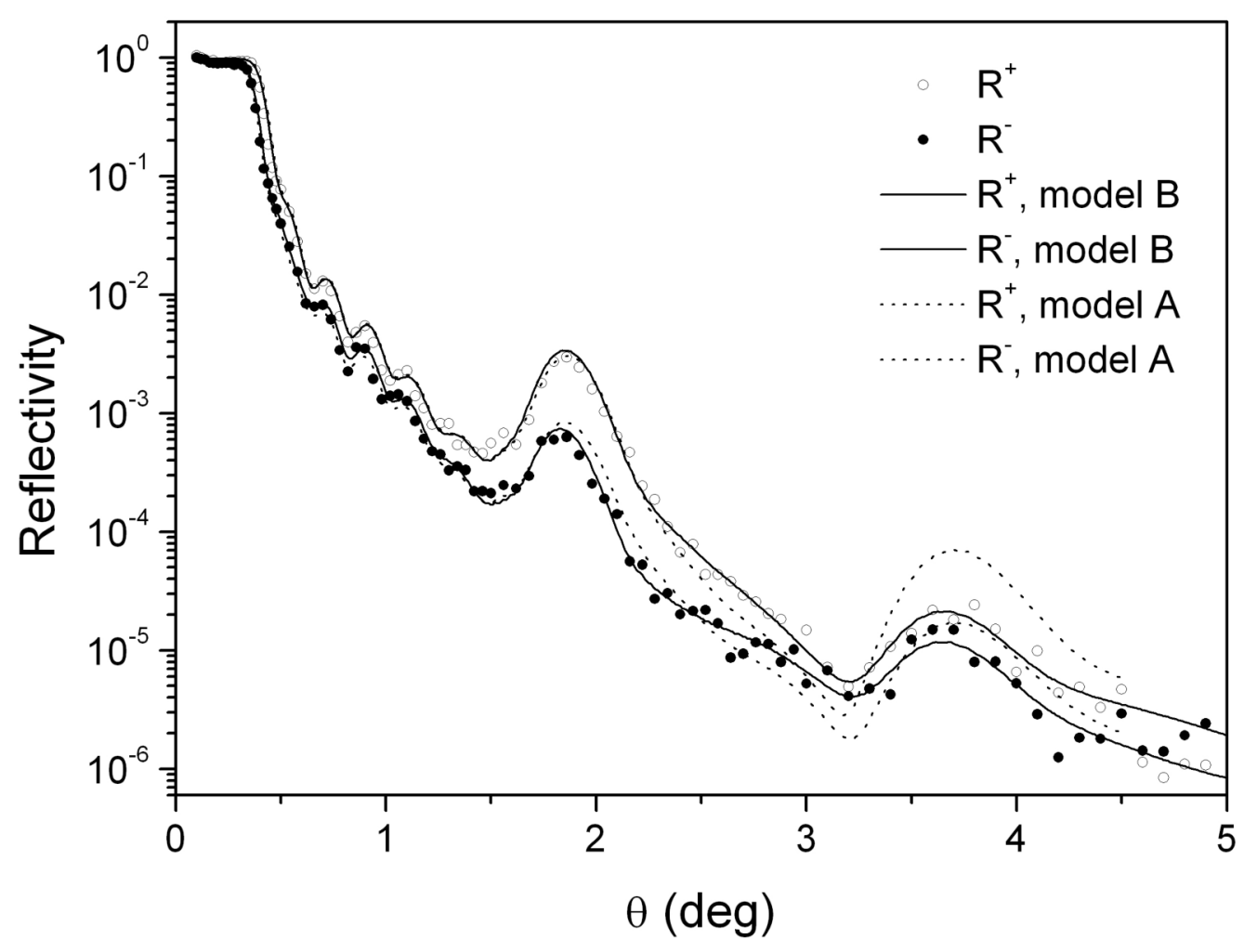

Figure 09 (Fig9.jpg) 


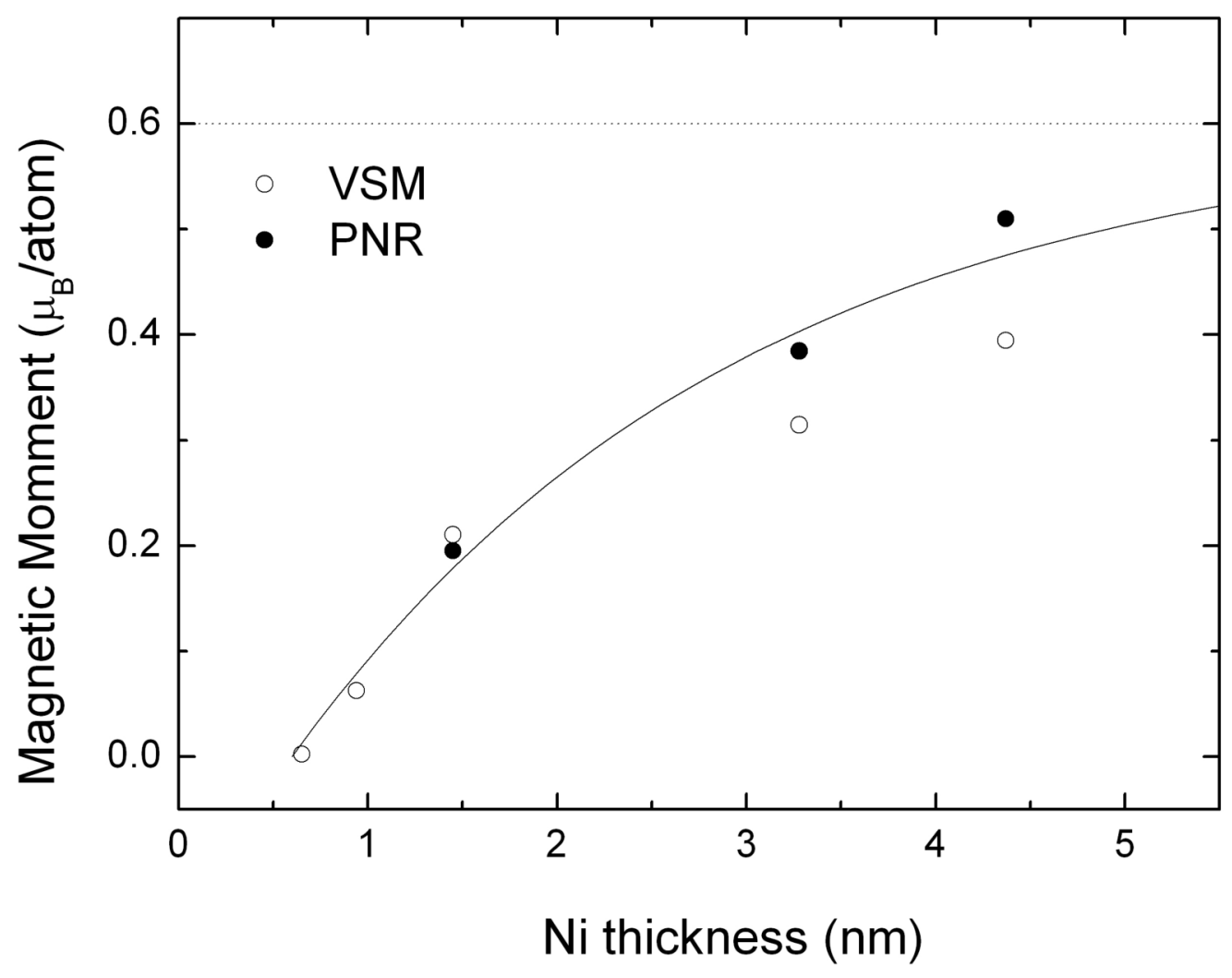

Figure 10 (Fig10.jpg) 